\title{
GA-A16402
}

UC-77

\section{IRRADIATION-INDUCED CREEP IN GRAPHITE: A REVIEW}

\author{
by \\ R. J. PRICE

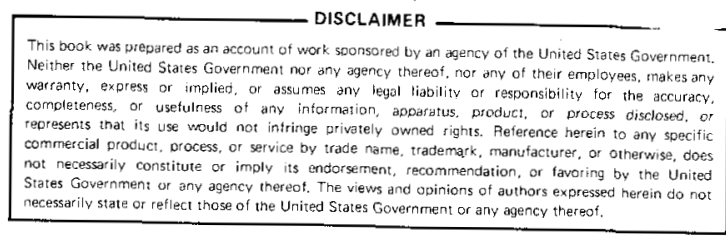 \\ Prepared under \\ Contract DE-AT03-76ET35301 \\ for the San Francisco Operations Office \\ Department of Energy
}

This decument is

WULICLY RELEASABLE GENERAL ATOMIC PROJECT 7400

Lanks.opill

Dote: $12 / 02 / 2 e^{5}$ DATE PUBLISHED: AUGUST 1981

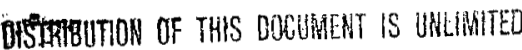

\section{GENERAL ATOMIC COMPANY}




\section{DISCLAIMER}

This report was prepared as an account of work sponsored by an agency of the United States Government. Neither the United States Government nor any agency Thereof, nor any of their employees, makes any warranty, express or implied, or assumes any legal liability or responsibility for the accuracy, completeness, or usefulness of any information, apparatus, product, or process disclosed, or represents that its use would not infringe privately owned rights. Reference herein to any specific commercial product, process, or service by trade name, trademark, manufacturer, or otherwise does not necessarily constitute or imply its endorsement, recommendation, or favoring by the United States Government or any agency thereof. The views and opinions of authors expressed herein do not necessarily state or reflect those of the United States Government or any agency thereof. 


\section{DISCLAIMER}

Portions of this document may be illegible in electronic image products. Images are produced from the best available original document. 


\begin{abstract}
Data on irradiation-induced creep in graphite published since 1972 are reviewed. Sources include restrained shrinkage tests conducted at Petten, the Netherlands, tensile creep experiments with continuous strain registration at Petten and Grenoble, France, and controlled load tests with outof-reactor strain measurement performed at Oak Ridge National Laboratory, Petten, and in the United Kingdom. The data provide reasonable confirmation of the linear viscoelastic creep model with a recoverable transient strain component followed by a steady-state strain component, except that the steady-state creep coefficient must be treated as a function of neutron fluence and is higher for tensile loading than for compressive loading. The total transient creep strain is approximately equal to the preceding elastic strain. No temperature dependence of the transient creep parameters has been demonstrated. The initial steady-state creep coefficient is inversely proportional to the unirradiated Young's modulus of the graphite, and the decline in creep coeffictent at high fluences parallels the increase in Young's modulus. There is no conclusive evidence for a flux-dependency of the creep coefficient. The creep coefficient increases with irradiation temperature, but the temperature dependence is still not well defined. For a uniaxially stressed specimen the ratio between the transverse creep strain and the longitudinal creep strain is about 0.3 , with a tendency toward a higher strain ratio at high strains. Tensile creep strain tends to reduce the thermal expansivity, while compressive creep strain has the opposite effect. Poisson's ratio is reduced by compressive creep strain. The effects of creep strain on Young's modulus and tensile strength are negligible. Creep equations recommended for mechanical design of graphite reactor components are presented.
\end{abstract}


CONTENTS

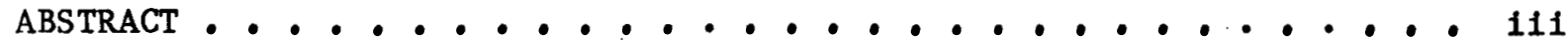

1. INTRODUCTION ...................... 1

2. VISCOELASTIC CREEP MODEL . . . . . . . . . . . . . . . . 3

3. THEORIES OF IRRADIATION CREEP . . . . . . . . . . . . 6

4. EXPERIMENTAL TECHNIQUES . . . . . . . . . . . . 10

4.1. Restrained Shrinkage . . . . . . . . . . . 10

4.2. Fully Instrumented Creep Tests . . . . . . . . . . . 12

4.3. Controlled Load Tests with Out-of-Reactor

Strain Measurement . . . . . . . . . . . . 16

5. SUMMARY OF EXPERIMENTAL RESULTS . . . . . . . . . . . . . 21

5.1. Transient Creep and Recovery . . . . . . . . . . . 21

5.2. Steady State Creep . . . . . . . . . . . . 32

5.2.1. Dependence on Stress . . . . . . . . . . 32

5.2.2. Dependence on Material Properties ........ 33

5.2.3. Dependence on Temperature and Neutron Flux . . . . 38

5.2.4. Dependence on Neutron Fluence . . . . . . . 45

5.3. Transverse Strain Ratio . . . . . . . . . . . 48

5.4. Effect of Creep Strain on Physical Properties . . . . . 49

5.4.1. Thermal Expansivity ............. 49

5.4.2. Young's Modulus .............. . . 54

5.4.3. Poisson's Ratio ............... 56

5.4.4. Strength and Faflure Strain .......... 56

5.4.5. Irradiation-Induced Dimensional Change Rates . . . 58

6. RECOMMENDED DESIGN EQUATIONS . . . . . . . . . . . . . 61

6.1. Creep Model ...................... 61

6.2. Transient Creep . . . . . . . . . . . . . . . 61

6.3. Steady State Creep .................. 62

6.4. Tranverse Strain Ratio . . . . . . . . . . . 63

6.5. Effect of Creep Strain on Physical Properties. . . . . . 65

7. REFERENCES . . . . . . . . . . . . . . . . 66 


\section{FIGURES}

1. Rheological model for irradiation-induced creep in graphite . . 4

2. Creep specimen and restraining pads for restrained

shrinkage tests ....................... 11

3. Example of the stress build-up and dimensional changes of a graphite creep assembly as a function of neutron fluence. . . . 13

4. Schematic illustration of $R-135$ continuous-registration creep assemb1y. . . . . . . . . . . . . . . . 15

5. Cross-sectional view of in-core portion of compressive

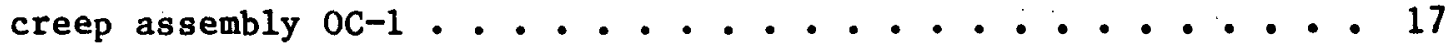

6. Schematic illustration of DISCREET creep capsule assembly . • • 19

7. Creep strain record of experiment ORPHEE $03 . . . . . . . .22$

8. Creep strain record of experiment FLACH 02. . . . . . . . . 23

9. Creep strain record of experiment FLACH 04. . . . . . . . 24

10. Creep strain record of experiment FLACH 03. . . . . . . . . 26

11. Creep strain record of experiment R-135 . . . . . . . . . 29

12. Creep strain record of experiment $D-166-01$ at $850^{\circ} \mathrm{C}$ with tensile stress of $6 \mathrm{MPa}$. . . . . . . . . . 30

13. Creep strain as a function of compressive stress for different graphites at a fluence of approximately $10^{21} \mathrm{n} / \mathrm{cm}^{2}$ (DNE). . . 34

14. Creep strain as a function of neutron fluence for ATR-2E graphite (axial orientation) at $500^{\circ} \mathrm{C}$ : (a) tension,

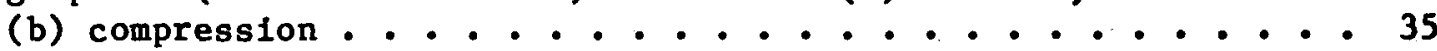

15. Steady-state irradiation creep data from restralned shrinkage tests: (a) creep coefficient as a function of temperature; (b) creep coefficient multiplied by initial Young's modulus as a function of temperature . . . . . . . . . . . . . 37

16. Steady-state irradiation creep data from restralned shrinkage tests: creep coefficient moultiplied by Initial Young's modulus for different flux ranges as a function of temperature ......................... 39

17. Composite plot of creep coefficient multiplied by inftial Young's modulus as a function of temperatures ......... 44

18. Creep coefficients divided by the value at $0.8-1.4 \times 10^{21}$ $\mathrm{n} / \mathrm{cm}^{2}$, DNE, as a function of neutron fluence for ATR-ZE graphite at $500^{\circ} \mathrm{C}$, with structural factor S . . . . . . . 47

19. Composite plot of transverse creep strain as a function of longltudinal creep strain. . . . . . . . . . . . 50 
20. Composite plot of thermal expansivity of creep specimens divided by the thermal expansivity of irradiated unstressed companion specimens, as a function of creep strain. . . . . . 52

21. Composite plot of thermal expansivity of creep specimens divided by the thermal expansivity of irradiated unstressed companion specimens, as a function of creep strain. . . . - . 53

22. Composite plot of Young's modulus of creep specimens divided by Young's modulus of irradiated unstressed companion specimens, as a function of creep strain. . . . . . . . . 55

23. Poisson's ratio of creep specimens divided by Poisson's ratio of irradiated unstressed companion specimens, as a function of creep strain. . . . . . . . . . . . 57

24. Tensile strength of creep specimens of pressed gilsocarbon graphite Irradiated in the Dragon reactor, as a function of tensile creep strain. . . . . . . . . . . . . . . . 59

25. Dimensional changes as a function of neutron fluence of UK isotropic graphite specimens subjected to a tensile or compressive load for the first part of the irradiation, with unstressed controls................ 60

1. Transient creep characteristics. . . . . . . . . . . . 27

2. Steady-state creep coefficients from CEA/KFA continuously measured creep tests... . . . . . . . . . . . . 41

3. Values for steady-state creep parameters . . . . . . . . . 64 


\section{INTRODUCTION}

Irradiation-induced creep in the graphite core and reflector components of a high-temperature gas-cooled nuclear reactor (HTGR) permits the relaxation of stresses arising from differential irradiation-induced shrinkage and differential thermal strains. The creep phenomenon needs to be well characterized for mechanical design calculations to be realistic.

A report written in 1972 (Ref. 1) reviewed the existing literature on irradiation creep in graphite relevant to HTGR conditions. The 1976 Petten conference on the measurement of irradiation-enhanced creep in nuclear materials (Ref. 2) included nine papers on irradiation creep in graphite, and provides an excellent overview of world-wide creep programs and measurement techniques. The present report reviews work published since 1972, including experiments intended to verify the basic viscoelastic creep model, refinements in the determination of creep parameters, and the effects of creep strain on physical properties. The report attempts to present the data in a form useful to designers; the experimental techniques and the theory of irradiation creep are only touched on briefly. Details of measurement techniques can be found in the papers in Ref. 2, while the theory of irradiation creep in graphite is discussed in a series of papers by Kelly and co-workers (Refs. 3 through 5).

Most of the original data reviewed in this report express neutron fluence in terms of the Dido nickel equivalent (DNE) fluence. Conversion to other fluence units are made as follows (Ref.6):

\footnotetext{
Equivalent fission fluence for damage in graphite $=1.77 \times$ DNE fluence.
} 
Fluence of neutrons with energy greater than $0.18 \mathrm{Mev}$ in a typical HTGR spectrum

$=1.42 \times$ DNE fluence. 


\section{VISCOELASTIC CREEP MODEL}

Virtually all the reported irradiation creep experiments have been analyzed in terms of a linear viscoelastic creep function which can be represented by the rheological model illustrated in Fig. 1. The Kelvin element (spring and dashpot in paralle1) represents the transient creep strain component, while the spring of the Maxwell element represents the elastic component and the dashpot of the Maxwell element represents the steady-state creep component. Two "black box" elements are shown in the model to represent the thermal strain and irradiation strain components, which are independent of applied stress. Figure $1(b)$ shows the mechanical strain response (disregarding the black box elements) when a constant stress is applied to a creep specimen for a time period and then removed. There is an instantaneous elastic strain, $\varepsilon^{E}$, which is followed by a period of transient creep. The transient creep strain saturates at $\varepsilon^{T}$ after a short interval. The steady-state creep strain, $\varepsilon^{S}$, increases linearly with neutron fluence. When the stress is removed, an elastic strain $\varepsilon^{R}$ is instantaneously recovered. $\varepsilon^{R}$ may be smaller than the original elastic strain, $\varepsilon^{E}$, because Young's modulus of graphite increases with neutron fluence. The transient creep strain, $\varepsilon^{T}$, is recovered over a short interval, but the steady-state creep strain, $\varepsilon^{S}$, is not recoverable. The total mechanical strain, $\varepsilon$, is given by the expression:

$$
\varepsilon=\frac{\sigma}{E_{0}}+\frac{a \sigma}{E_{o}}[1-\exp (-b \gamma)]+k \sigma \gamma,
$$

\footnotetext{
where $\sigma=$ applied stress,

$\gamma=$ fast neutron fluence, and$$
E_{O}=\text { initial value of Young's modulus. }
$$ 


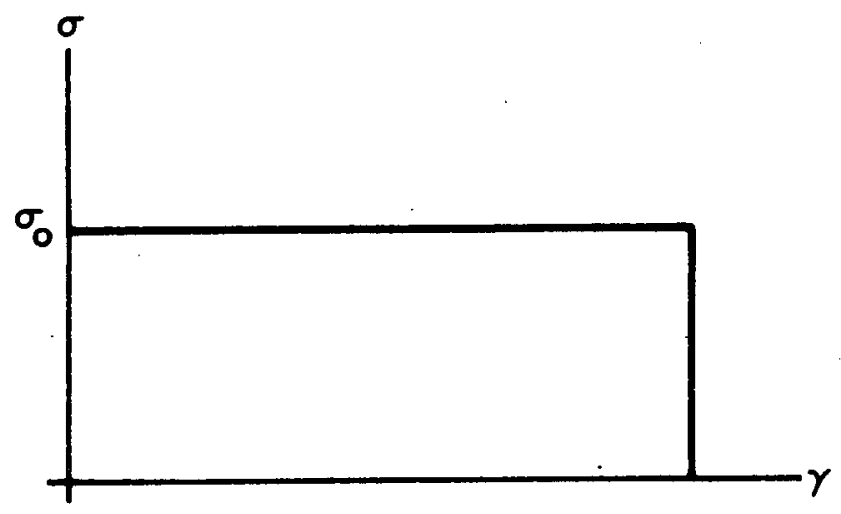

(a) STEP FUNCTION LOADING

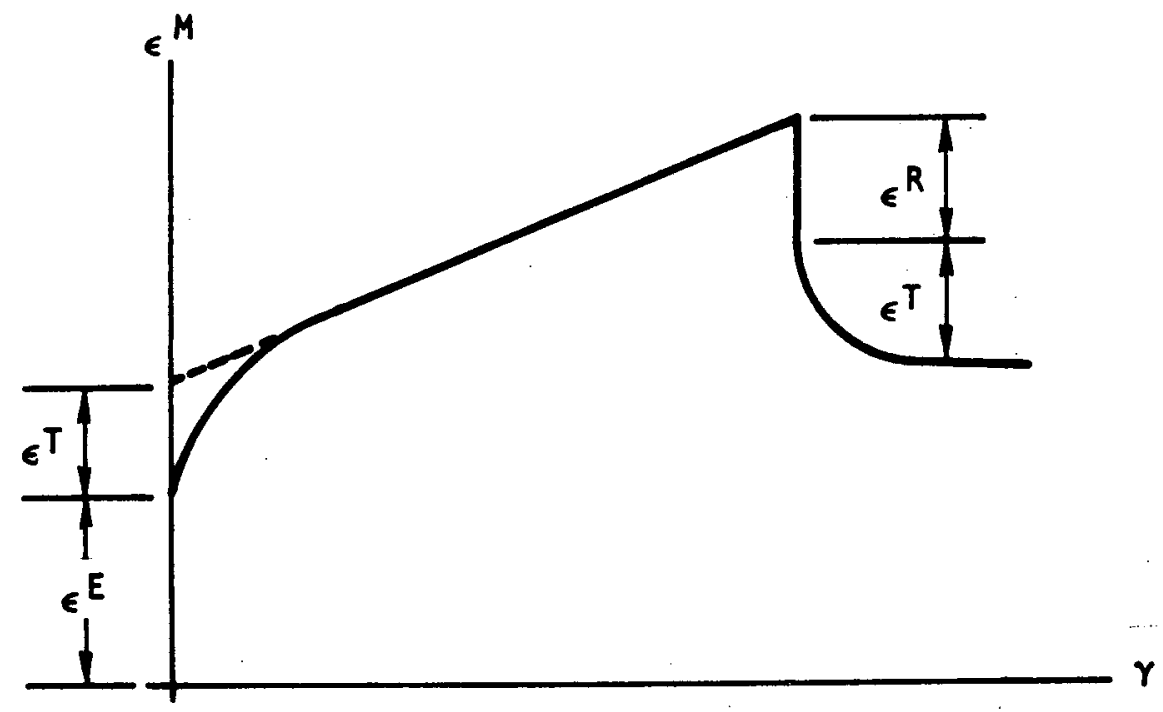

(b) STRAIN RESPONSE

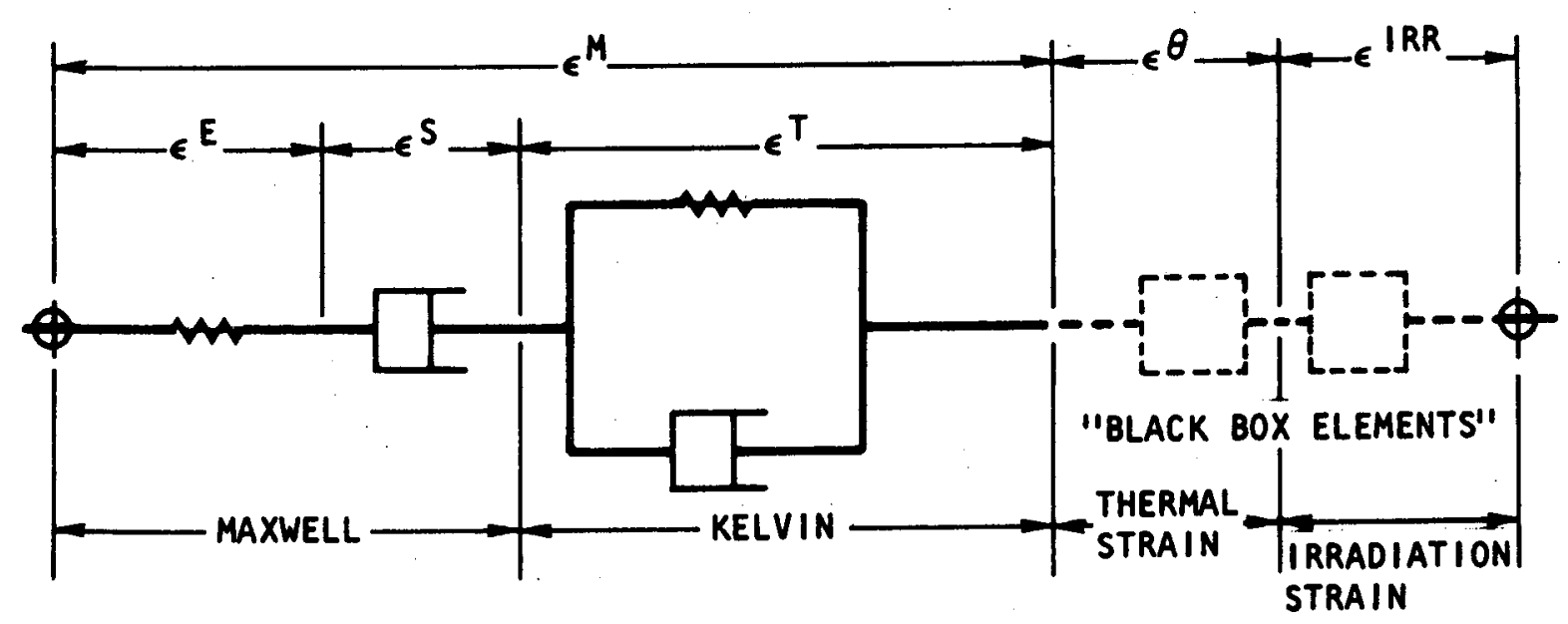

(c) MODEL

Fig. 1. Rheological model for Irradiation-induced creep in graphite 
The three material parameters that characterize the creep behavior of the graphite are

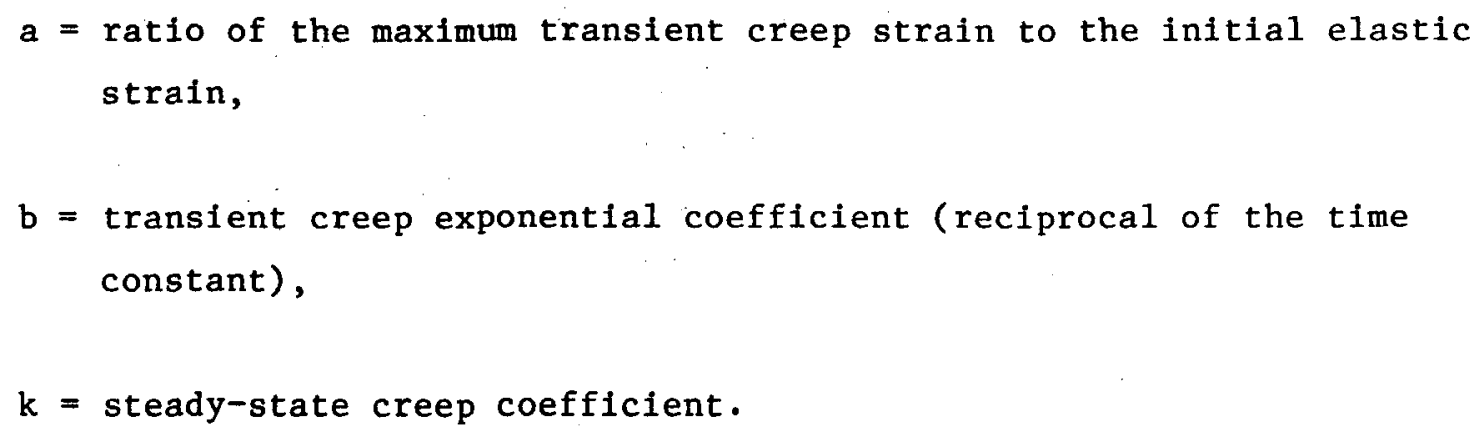
strain,

$b=$ transient creep exponential coefficient (reciprocal of the time constant),

$k=$ steady-state creep coefficient.

The extent to which the experimental data conform to Eq. 1 and to the rheological model of Fig. 1 is discussed in subsequent sections of this report.

Equation 1, as written, refers to uniaxial loading, which is the mode in which all experiments to date have been conducted. However, in several experiments the transverse strain was measured in addition to the strain in the loading direction. These data are described in Subsection 5.3. 


\section{THEORIES OF IRRADIATION CREEP}

Although a detailed discussion of the theory of irradiation creep is beyond the scope of this review, a brief outline may be useful in interpreting some of the experimental data.

The relationship between the macroscopic creep rate of polycrystalline graphite and the deformation of individual crystallites has been analyzed in papers by Kelly and co-workers (Refs. 3 through 5). The elastic deformation of polycrystalline graphite is dominated by shear parallel to the basal planes of the constituent crystallites. It may be assumed that creep deformation is likewise controlled by basal slip. Equating the work done by the macroscopic and microscopic creep rates leads to the following expression for $\mathrm{d} \varepsilon_{\mathrm{xx}} / \mathrm{d} \gamma$, the rate of change of creep strain in the $\mathrm{x}$ direction with respect to neutron fluence $\gamma$ :

$$
\frac{d \varepsilon_{x x}}{d \gamma}=K \sigma_{x x}\left(\frac{C_{44}}{E_{x x}}\right),
$$

where $\mathrm{K}=\mathrm{a}$ constant,

$$
\begin{aligned}
& \sigma_{\mathrm{xx}}=\text { the uniaxial stress in the } \mathrm{x} \text { direction, } \\
& \mathrm{C}_{44}=\text { the single crystal elastic constant for basal s'ear, and } \\
& \mathrm{E}_{\mathrm{Xx}}=\text { Young's modulus in the } \mathrm{x} \text { direction. }
\end{aligned}
$$

Equation 2 implies that, for the same irradiation conditions, the creep rate for different graphite grades and orientations will be inversely proportional to Young's modulus. It also implies that the creep rate will not be affected by those changes in Young's modulus that result from changes in $\mathrm{C}_{44}$ (such as the rapid initial rise in $\mathrm{E}_{\mathrm{xx}}$ at low neutron fluences), because the ratio $C_{44} / E_{x x}$ remains constant. However, the creep rate will be 
influenced by changes in $E_{X x}$ arising from changes in the structure of the graphite aggregate ( such as the slow rise in Young's modulus at high fluences or the reduction in Young's modulus, due to oxidation). Another prediction of the theory is that the ratio of lateral creep strain to longitudinal creep strain will be equal to the elastic Poisson's ratio.

The constant $\mathrm{K}$ in $\mathrm{Eq} \cdot 2$ is related to the strain rates in the individual crystallites. Two theories have been proposed to account for these microscopic strain rates. According to a model originally developed by Roberts and Cottre11 (Ref. 7) to explain irradiation-induced creep in uranium, creep is considered to result from the anisotropic dimensional changes of the crystallites causing internal yielding. The creep strain rate, $d \varepsilon_{x x} / d \gamma$, is given by

$$
\frac{d \varepsilon_{x x}}{d \gamma} \simeq \frac{\sigma_{x x}}{Y}\left[\begin{array}{l}
1 \\
X_{c}
\end{array}\left(\frac{d_{c}}{d \gamma}\right)-\frac{1}{X_{a}}\left(\frac{d_{a}}{d \gamma}\right)\right],
$$

where $\quad Y=$ the yield stress of the crystallites, and

$\mathrm{x}_{\mathrm{c}}$ and $\mathrm{x}_{\mathrm{a}}=$ the crystallite dimensions in the $\mathrm{c}$ and a directions, respectively.

The quantities $\left(1 / \mathrm{X}_{\mathrm{c}} \cdot \mathrm{dX}_{\mathrm{c}} / \mathrm{d} \gamma\right)$ and $\left(1 / \mathrm{X}_{\mathrm{a}} \cdot \mathrm{dX}_{\mathrm{a}} / \mathrm{d} \gamma\right)$ are fairly we11 known functions of irradiation temperature obtained from experiments on graphite crystals and highly oriented pyrolytic graphite. However, there is no independent estimate of the internal yield stress, $Y$, which is likely to be a function of temperature and fluence.

An alternative model proposed by Kelly and Foreman (Ref. 4) assumes that basal slip in the crystallites is activated by dislocations moving through an array of pinning points that are continually being created and destroyed by irradiation. The theory predicts that the steady-state creep coefficient should be directly proportional to the dislocation density and 
inversely proportional to the pinning point density. An additional prediction is that the linear relationship between creep rate and stress would break down at high stresses.

The relationship between macroscopic and microscopic strain creep rates (Eq. 2) seems to be fairly well supported by experimental evidence. The dependence of creep coefficient on Young's modulus, and the change in creep rate in highly irradiated or oxidized specimens, agree at least qualitatively with the predictions, but the lateral-to-longitudinal creep strain ratios tend to be greater than Poisson's ratio (Refs. 3 and 5).

Agreement between experiment and the two theories of microscopic creep rates is more controversial. The observed temperature dependence of the steady-state creep coefficient is roughly similar to the temperature dependence of the crystallite dimensional change rates, and this similarity has been cited as support for the Roberts-Cottre11 mechanism (Eq. 3). However, agreement would be expected only if the internal yield stress, $Y$, is independent of temperature. The Kelly-Foreman mechanism does not explicitly predict the temperature dependence of the creep coefficient, and it implies that the dislocation density must be similar in all graphites. The creep rate calculated from the Kelly-Foreman dislocation pinning-unpinning model appears in reasonable agreement with experiments. In one experiment specifically designed to test the alternative models, the irradiation creep rate of a standard nuclear graphite was compared with the creep rate of graphite doped with 0.27 wt \% boron (Ref. 8). Creep rates in the two materials were similar, despite a factor of 3 higher crystallite dimensional change rate in the boron-doped graphite. This result appears to favor the Kelly-Foreman model over the Roberts-Cottrell model.

A semiempirical model for irradiation-induced creep in graphite has been proposed by Cords (Ref. 9) as an extension of his model for the irradiation-induced changes in physical properties, which assumes three saturating atomic processes with different activation energies (Ref. 10). 
By adjusting the "importance factors" for the different processes, the reported temperature dependence of the steady-state creep coefficient could be matched. Similarly, the strain-fluence curves from the French stepchange creep experiments (FLACH-02, -03 , and -04 and ORPHEE-03) could be matched through the fitting of free parameters. However, the temperature dependence of the creep coefficlent predicted by the fitted parameters from the step-change experiments differed considerably from the observations; in one case the creep coefficient was predicted to become negative below about $1000^{\circ} \mathrm{C}$. It seems that the model needs further development before it can be used for extrapolating experimental data into unexplored temperature and fluence regions. 


\section{EXPERIMENTAL TECHNIQUES}

\subsection{RESTRAINED SHRINKAGE}

In this technique a dumbbell-shaped tensile specimen is fitted with a split cylindrical restraining pad made from a different grade of graphite (Fig. 2). The pad material is chosen so that the difference in irradiationinduced shrinkage between the specimen and the pad subjects the specimen to a tensile stress during irradiation. A modified version can be used to stress a specimen in compression. After the test, the difference in shrinkage between the specimen and an unrestrained companion irradiated in the same capsule at the same temperature gives the irradiation-induced creep strain. The end-of-life stress can be estimated by heating the specimen plus pad assembly to the irradiation temperature and measuring the specimen expansion, and then repeating the test with the restraining pads removed. The difference in thermal strain gives the elastic strain present at the end of irradiation. A final measurement of the tensile stress-strain curve gives the corresponding stress. The whole assembly can be reirradiated to obtain additional data.

This method was developed by the ECN, Petten (the Netherlands) laboratory and has been used extensively to generate creep data on several hundred specimens of many varieties of graphite (Refs. 11 through 14). Its principal advantages are that the restrained shrinkage assemblies are selfactuating and require no external loading device, the capsule experiments are fairly inexpensive, and up to 50 specimens can be included in one capsule. The disadvantages are that the load on the specimen varies during the test and is only known at the end of 11 fe (from an indirect measurement out of the reactor), and the method of analyzing the results assumes a specific creep model. This method is therefore most suitable for generating a large number of measurements when the creep laws have been determined from other, 


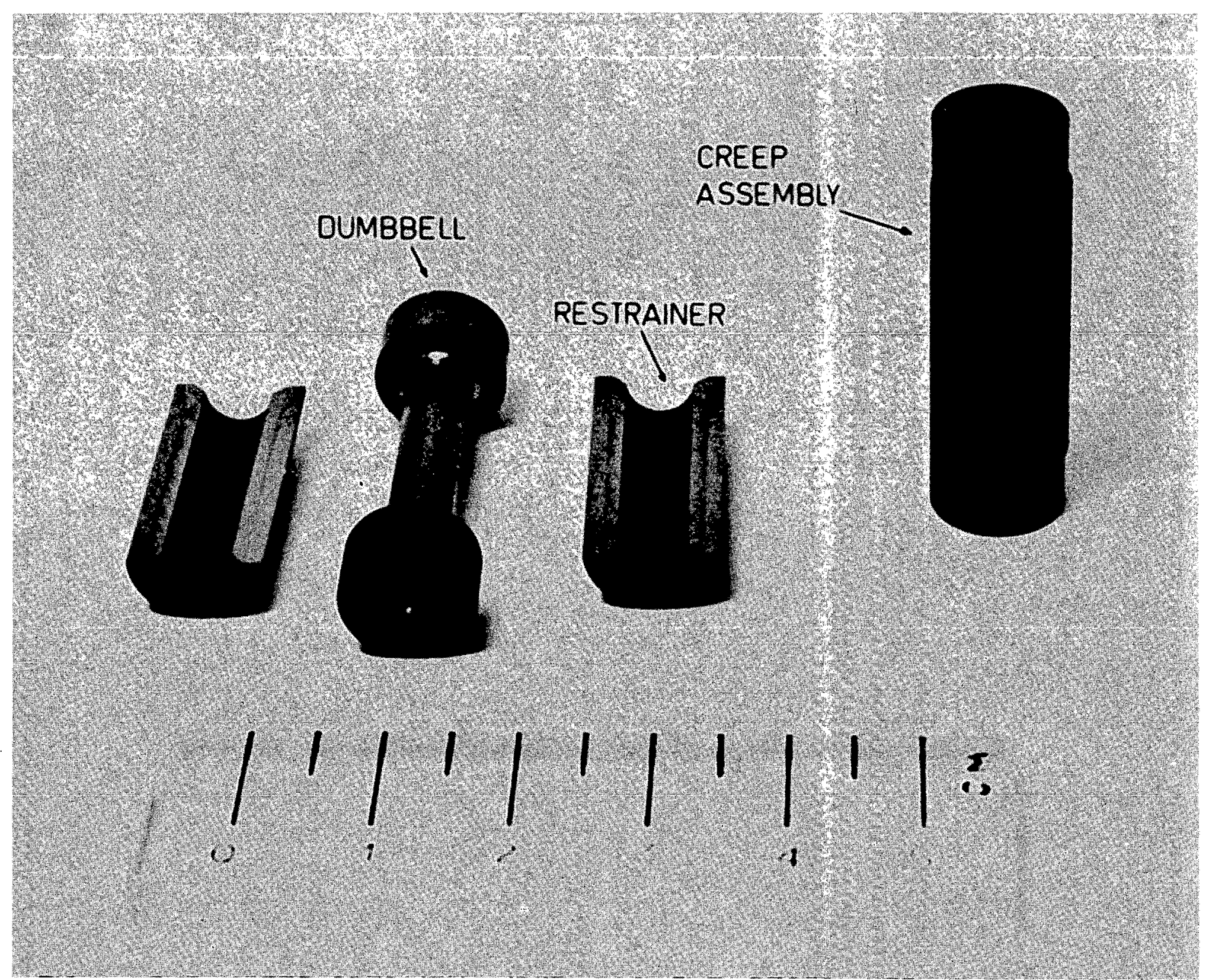

Fig. 2. Creep specimen and restraining pads for restrained shrinkage tests (from Ref. 12) 
more direct, experiments. The method cannot be used at high fluences where dimensional change rates reverse ("turn around"), and is limited at low temperatures (below $500^{\circ} \mathrm{C}$ to $600^{\circ} \mathrm{C}$ ) because of low shrinkage rates.

The procedure for analyzing the test results is explained in detall (in Ref. 12). Briefly, the unrestrained dimensional changes in the specimen and the pad material are expressed as polynomial functions of fluence. Using the measured end-of-iradiation stress as input, an iterative calculation is performed to derive a value for $k$, the steady-state creep coefficient (Eq. 1). As a check, the restrained dimensional changes in the specimen and restraining pad can be compared with the calculation. An example of the measured and calculated stress buildup and dimensional change is shown in Fig. 3.

Aside from the necessity for assuming a specific model, this technique is subject to several sources of error. The stress determination is very sensitive to the irradiation temperature of the particular assembly, and the dimensional change-versus-fluence curve for a particular specimen may deviate from the assumed polynomial expression because of statistical variations. The assemblies must be machined to very close tolerances and must be reassembled in precisely the same way after out-of-reactor measurements. The differential thermal expansion measurement, necessary to determine the end-of-life stress, requires high precision. Finally, the tensile test on the dumbbell specimen is performed at room temperature, but the data are assumed to apply at irradiation temperature. The cumulative effect of the sources of error could be large. No formal error analysis has been pub1 ished, but an accuracy of $\pm 20 \%$ for the determination of $k$ has been claimed (Ref. 15).

\subsection{FULLY INSTRUMENTED CREEP TESTS}

The most fundamental, but also the most difficult, method for measuring in-reactor creep is to use a fully instrumented in-reactor uniaxial creep 

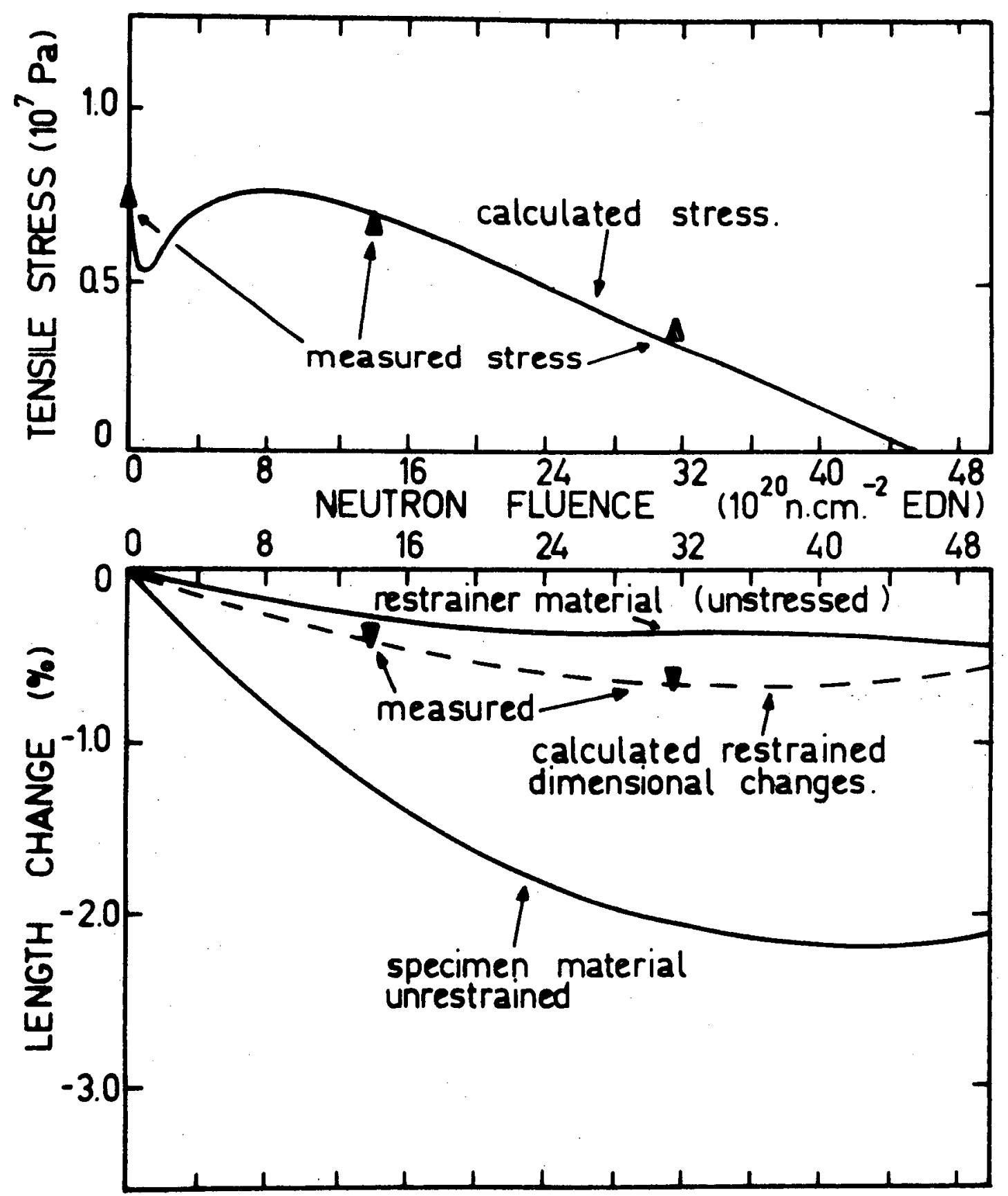

Fig. 3. Example of the stress build-up and dimensional changes of a graphite creep assembly as a function of neutron fluence (from Ref. 12) 
assembly in which the specimen can be subjected to a known load and the strain recorded as a function of neutron fluence.

This technique has been applied to reactor graphites in tests in the Siloé reactor, Grenoble, France (Refs. 16 through 19) and in the High Flux Reactor, Petten, the Netherlands (Refs. 20 through 22). A single tensile specimen is loaded through pneumatic bellows and a sensor is used to measure the difference in length between the tensile specimen and an unstressed reference specimen. Figure 4 shows a schematic illustration of the R-135 creep experiment at Petten. The unstressed reference specimen consists of a pair of half shells fitting around the cylindrical gauge section of the tensile specimen. A measuring sensor is located between the head of the tensile specimen and the top of the reference specimen. The sensor can be moved up and down by actuating a second set of pneumatic bellows; the motion is recorded by a pair of linear displacement transducers. The French FLACH creep capsules used at Grenoble operate on similar principles, except that double sensors are used (one for each half of the split-shell reference specimen) and displacements are measured with a microwave resonant cavity. In the French ORPHEE creep capsules the tensile specimen and reference specimen are placed side by side and their length changes are measured by two separate sensor rods coupled to transducers. The displacements are actually measured with a motor-driven miclometer, the transducers serving only as null detectors.

This technique is capable of high precision strain measurements (displacements of a few microns can be reliably recorded) at short intervals, revealing fine details of the creep curve. The load is known and can be changed at will; the temperature can be changed over a limited range. Thermal expansion and stress-strain measurements can be made in situ. The principal disadvantages are the high cost and complexity of the rigs, the limitation of one specimen to a capsule, and the vulnerability of the single tensile specimen to fracture from an accidental overload. 


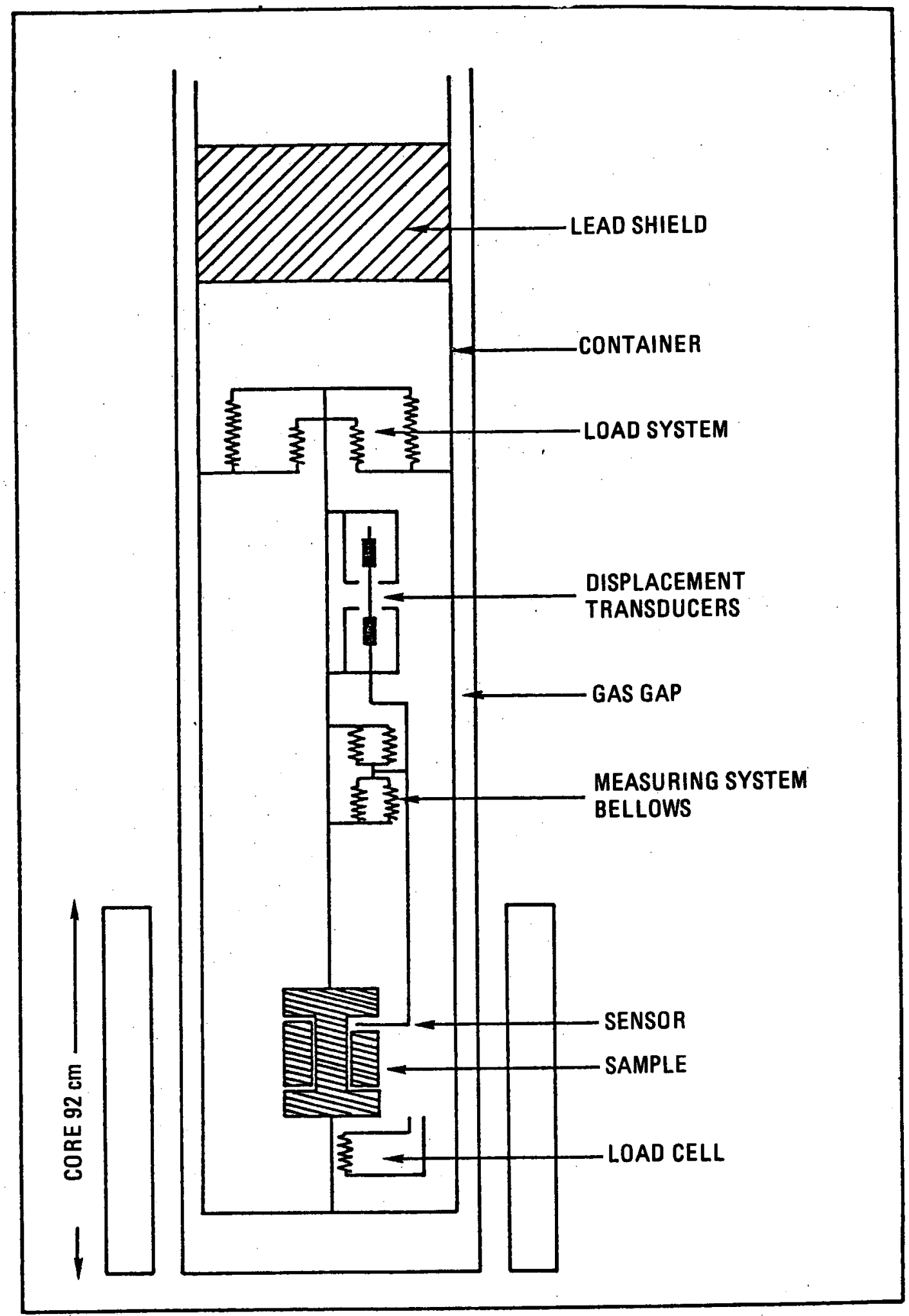

Fig. 4. Schematic 11lustration of R-135 continuous-registration creep assembly (from Ref. 20) 
In spite of the inherently high precision of the measurement technique, corrections have to be made for dimensional changes in the sensor material and for the difference in unrestrained shrinkage between the tensile specimen and reference specimen arising from their different length. These corrections are obtained from the average dimensional change-versus-fluence curves for the materials being tested; differences between the individual specimen behavior and the average curves are estimated from the final outof-reactor dimensional measurements. The sources of error are discussed in Ref. 19. Possible variations in individual specimen shrinkage rates could contribute an error of $\pm 10 \%$ to the values of the creep coefficient, $k$; and uncertainties in the measurements of fluence, load, and displacement could increase the uncertainty in the absolute value of $k$ to $\pm 25 \%$.

\subsection{CONTROLLED LOAD TESTS WITH OUT-OF-REACTOR STRAIN MEASUREMENT}

To increase the number of specimens tested while retaining the advantage of a controlled load, strings of tensile or compressive specimens loaded in series can be irradiated together with unstressed companions. Creep strains are determined from the difference in dimensions of the stressed and unstressed specimens when the irradiation capsule is disassembled. Curves of creep strain versus fluence can be constructed by repeated encapsulation and reirradiation of the same specimens, augmented (in the case of isothermal capsules) by data from specimens in different axial locations which receive different neutron exposures.

At present two series of graphite creep experiments of this type are being conducted, one at Oak Ridge National Laboratory and one at the Euratom Joint Research Center, Petten. Three capsules in the oc-series of compressive creep tests have been irradiated in the Oak Ridge Reactor (Refs. 23 through 28). Figure 5 shows a cross section of the OC-1 capsule. The capsule contains four columns of 14 cylindrical graphite specimens; two of the columns are subjected to a compressive load applied by pneumatic bellows and the other two are unstressed. The capsules are designed to operate isothermally at a nominal temperature of $600^{\circ}$ or $900^{\circ} \mathrm{C}$. A load cell is located 

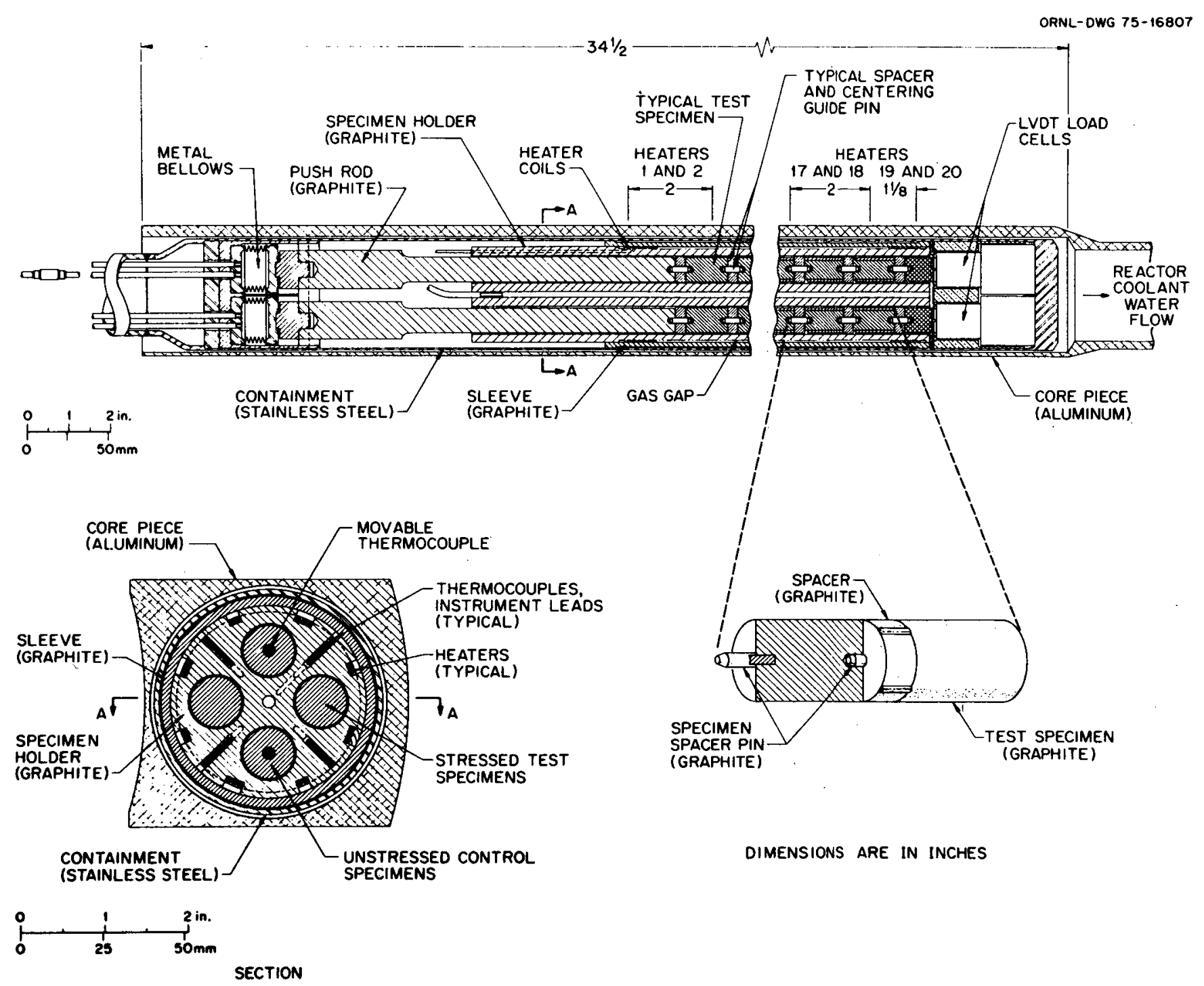

Fig. 5. Cross-sectional view of in-core portion of compressive creep assembly OC-1 (from Ref. 23) 
at the opposite end of each loaded column to the bellows to verify that the load is transmitted along the specimen train without binding. In the first capsule some binding occurred, but this was corrected in subsequent capsules.

The DISCREET series of capsule experiments being conducted at the Euratom laboratory, Petten (Refs. 29 through 33), uses principles similar to those of the oc-series. Three individually controlled specimen columns are irradiated simultaneously in reloadable thimbles (Fig. 6). Each column consists of either 5 tensile specimens or 10 compression specimens, together with unstressed reference specimens. The temperature is maintained by gasgap control. In a complete test series the specimens would be irradiated in four increments, with dimensional measurements being made between each increment. Along one specimen column there are flux differences of $30 \%$ for tensile specimens and $60 \%$ for compressive specimens.

Compared to creep experiments with continuous strain registration, the main disadvantage of this technique is that creep strain data points for one specimen are measured only at wide fluence intervals. To obtain more points for analysis, data from all the specimens in a column, incorporating the axial range in fluences, are usually included. If there is any flux dependence of the creep rate, this plotting method may obscure it.

Because the specimen strains are obtained from direct dimensional measurements in the laboratory, the measuring precision is good. The measurements must be corrected for irradiation-induced changes in thermal expansivity and Young's modulus. The stress applied to the end of the specimen column is known from the gas pressure in the bellows, which is held constant to within a few percent. However, any sticking or binding in the load train induces uncertainty; binding is more likely to occur in compression than in tension. The temperature along the specimen column of both the OC-capsules and the Petten capsules can be held constant to within about $\pm 30^{\circ} \mathrm{C}$ (Refs. 24 and 30). Since the creep strain is obtained from the difference in shrinkage between the stressed specimen and the unstressed reference specimen, 

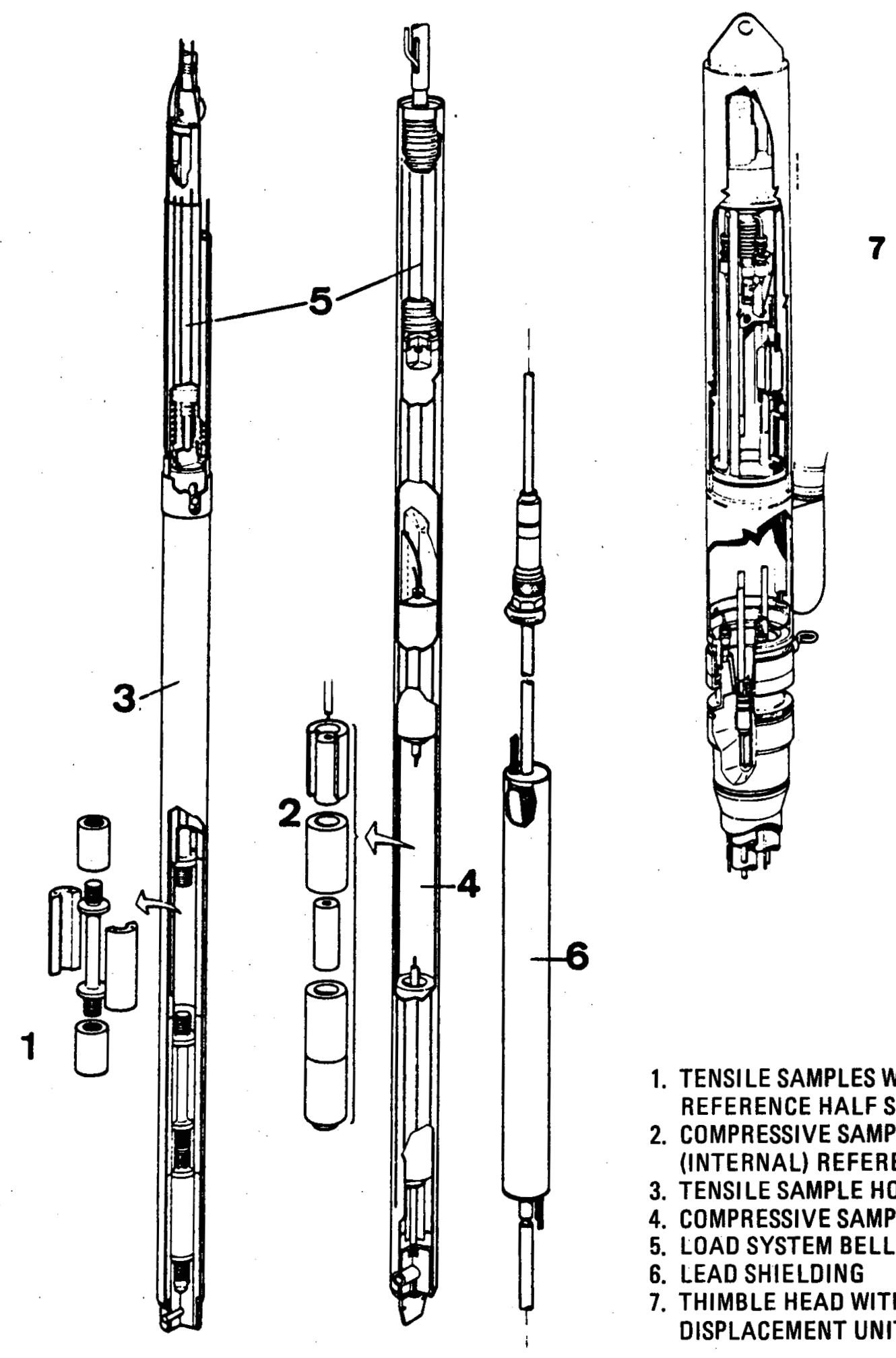

1. TENSILE SAMPLES WITH REFERENCE HALF SHELLS

2. COMPRESSIVE SAMPLE WITH (INTERNAL) REFERENCE PIECE

3. TENSILE SAMPLE HOLDER (2X)

4. COMPRESSIVE SAMPLE HOLDER

5. LOAD SYSTEM BELLOWS

6. LEAD SHIELDING

7. THIMBLE HEAD WITH DISPLACEMENT UNIT

\footnotetext{
Fig. 6. Schematic 11lustration of DISCREET creep capsule assembly (from Ref. 30)
} 
the absolute accuracy is limited by the statistical scatter in shrinkage determinations. 


\section{SUMMARY OF EXPERIMENTAL RESULTS}

\subsection{TRANSIENT CREEP AND RECOVERY}

The fully instrumented creep tests at Grenoble and Petten provide detailed records of the transient creep strain at start-up and at load increments, and of the recovery of the creep strain when the load is removed. Controlled load tests with out-of-reactor strain measurements can provide an estimate of the total transient creep strain by extrapolating plots of strain versus fluence back to zero fluence, but the extrapolation procedure is not very accurate, and these tests give no estimate for the transient creep exponential coefficient b (Eq. 1), unless the fluence increments are very short.

An analysis of four fully instrumented creep tests conducted at Grenoble, FLACH-02, -03 , and -04 , and ORPHEE-03, is contained in Ref. 19. The specimens in all four tests were made from coal tar pitch - coke graphite: Sigri grade AS2-M-500 in FLACH-02, Sigri grade AS2-F-500 in FLACH-04, and Pechiney $\mathrm{P}_{3} \mathrm{JHAN}$ in FLACH-03 and ORPHEE-03. The creep curves are shown in Figs. 7 through 10. In the ORPHEE-03 (Fig. 7) test the mean operating temperature was $945^{\circ} \mathrm{C}$. The stress was held at $2.5 \mathrm{MPa}$ for the first irradiation period, then lowered to $0.5 \mathrm{MPa}$, then increased to $4.5 \mathrm{MPa}$, then reduced to $0.5 \mathrm{MPa}$. A third irradiation step at a higher stress is not depicted because of instrumentation failure. In test FLACH-02 (Fig. 8), the temperature was raised from $893^{\circ}$ to $1088^{\circ} \mathrm{C}$ during the second irradiation period, and reduced to $893^{\circ} \mathrm{C}$ for the third period. Finally, the rig was moved to another reactor test hole and reirradiated at $845^{\circ} \mathrm{C}$ in a neutron flux lower by a factor of three. In all four steps the stress was set at 4.9 to $5.0 \mathrm{MPa}$. In test FLACH-04 (Fig. 9), the temperature was held constant at $895^{\circ} \mathrm{C}$ while the stress was increased from $2.8 \mathrm{MPa}$ to $4.9 \mathrm{MPa}$ to $7.0 \mathrm{MPa}$ in the first three steps. For the final step, the rig was 


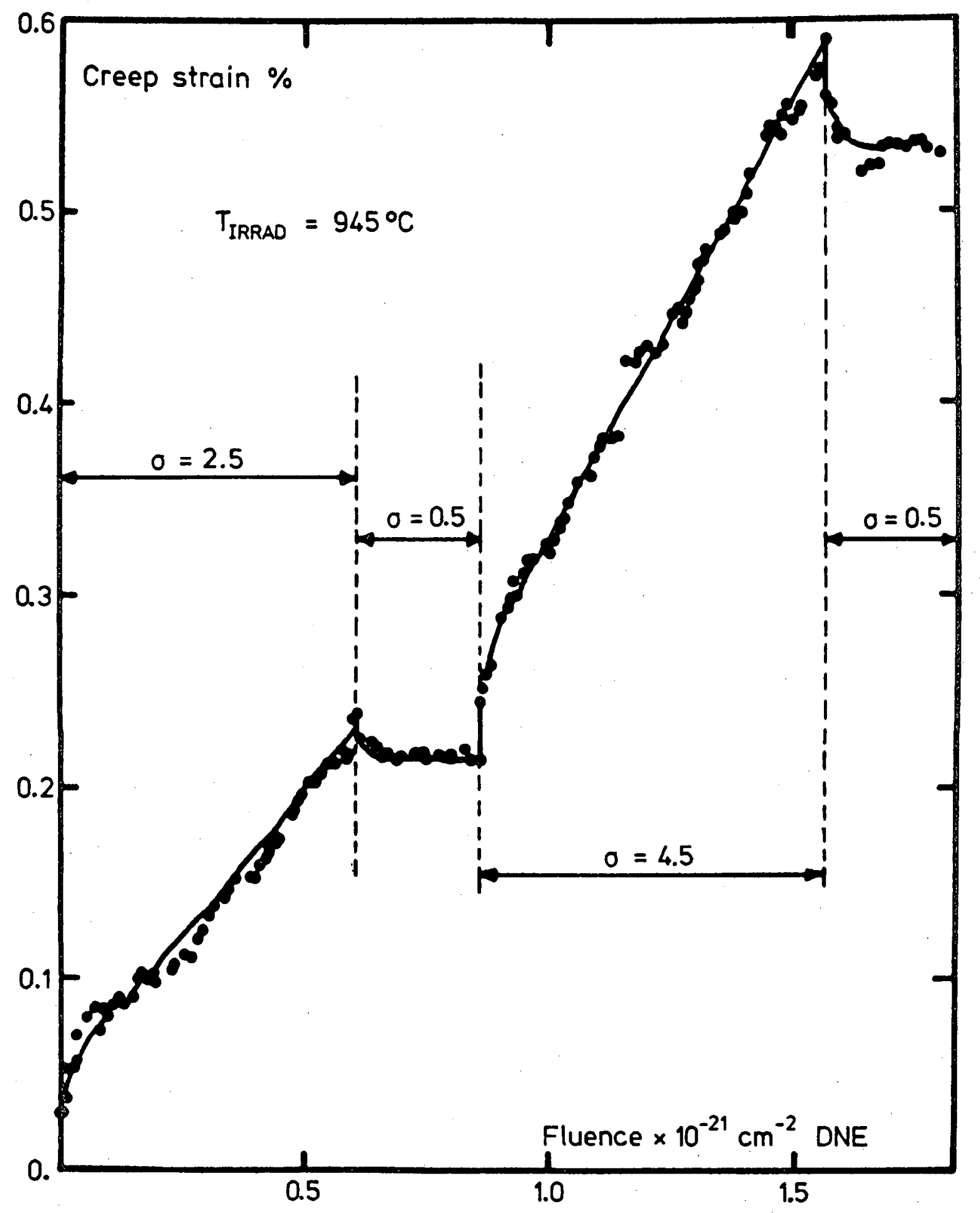

Fig. 7. Creep strain record of experiment ORPHEE 03 (from Ref. 19) 


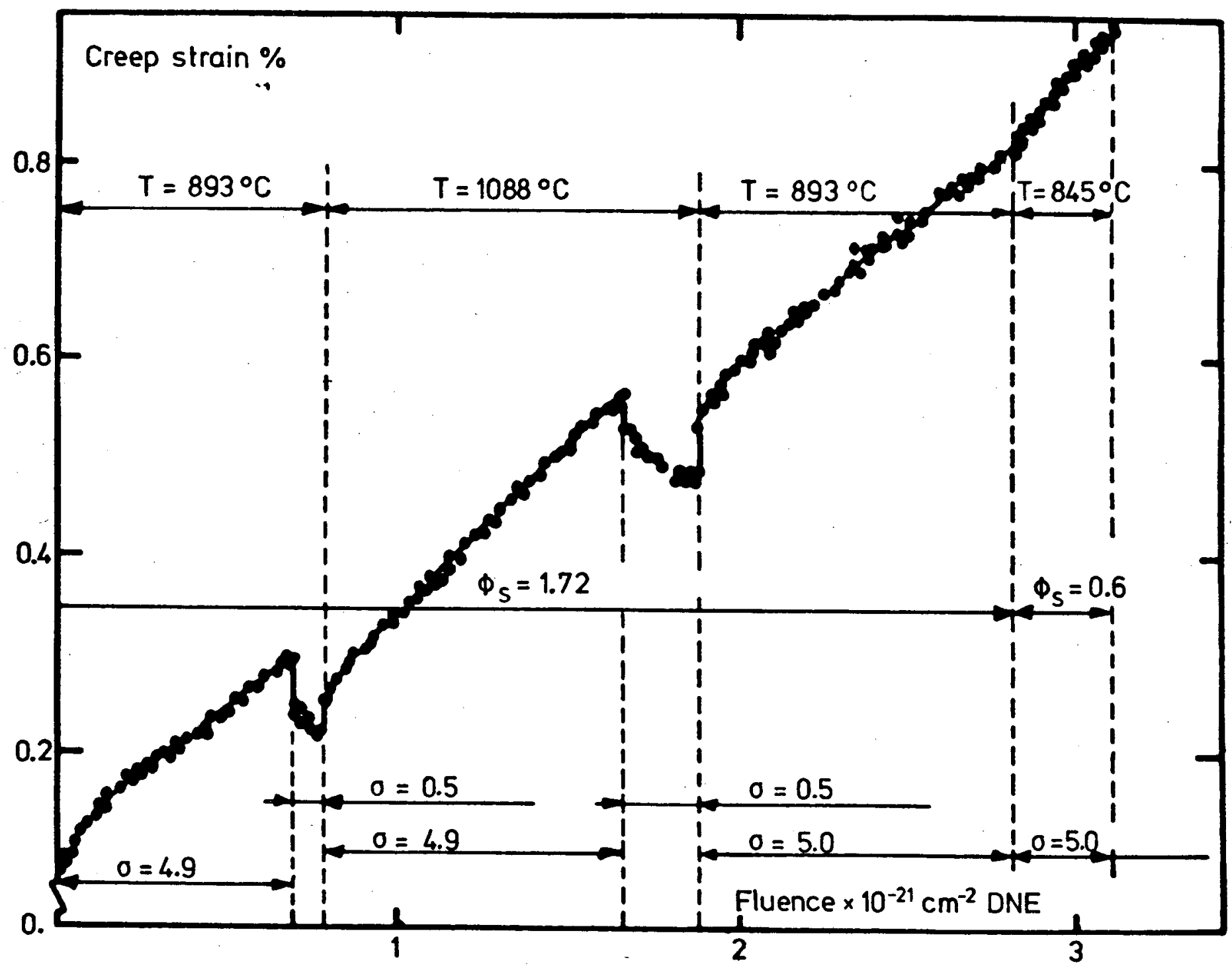

Fig. 8. Creep strain record of experiment FLACH 02 (from Ref. 19) 


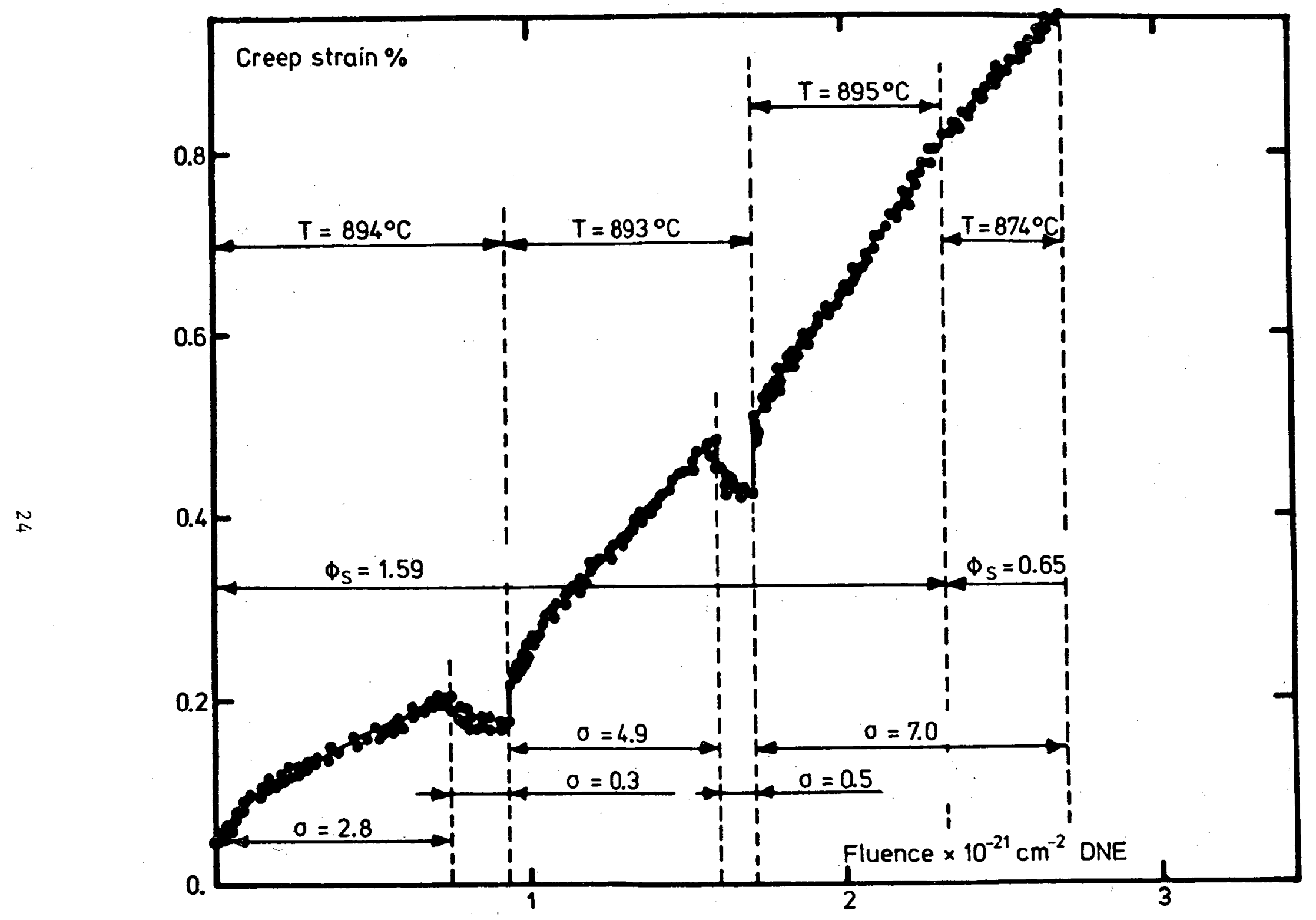

Fig. 9. Creep strain record of experiment FLACH 04 (from Ref. 19) 
reirradiated in the low flux test hole at $874^{\circ} \mathrm{C}$, under a stress of $7.0 \mathrm{MPa}$. Test FLACH-03 (Fig. 10) followed a similar pattern to FLACH-02, except that there was no low flux step.

Taken together, these four experiments provide direct verification of several points implicit in the rheological model shown in Fig. 1. All irradiation steps at a constant stress level show a saturating transient creep followed by steady-state creep. When the stress is reduced during irradiation, the instantaneous elastic recovery is followed by a slower recovery of the transient creep. The recovery time appears similar to the saturating time for transient creep.

The transient creep parameters calculated by a least-squares fitting method from the four experiments are shown in Table 1, taken from Ref. 19. The first line in the table shows the average ratio of the total transient creep strain to the preceding elastic strain (a in Eq. 1). The ratios range between 0.75 and 1.45 , averaging 1.10 . The second line shows the ratio of the total recovered creep strain to the preceding transient creep strain. The values range from 0.5 to 1.5 . Since partition of the recovered strain between the instantaneous elastic recovery and the slower creep recovery is somewhat arbitrary, the third line shows averaged ratios of the total recovered strain to the sum of the preceding elastic and transient creep strains. With the exception of the FLACH-02 results, the ratios range from 0.7 to 0.8 , compared with a theoretical maximum of 0.9 (because the shut-down stress is $10 \%$ of the preceding stress). Since the recovered strain would be expected to increase if the recovery period were extended, these results are consistent with full recovery of the transient creep strain. The final line in Table 1 shows the averaged transient creep exponential coefficient ( $b$ in Eq. 1). The values range from 0.15 to $0.4 \times 10^{-19}\left(\mathrm{n} / \mathrm{cm}^{2} \text {, DNE }\right)^{-1}$, with an average of $0.3 \times 10^{-19}$.

A continuously monitored tensile creep experiment using near-isotropic petroleum coke graphite (Great Lakes Carbon Corporation grade H-451) was conducted at Petten under the designation R-135. The same specimen was 


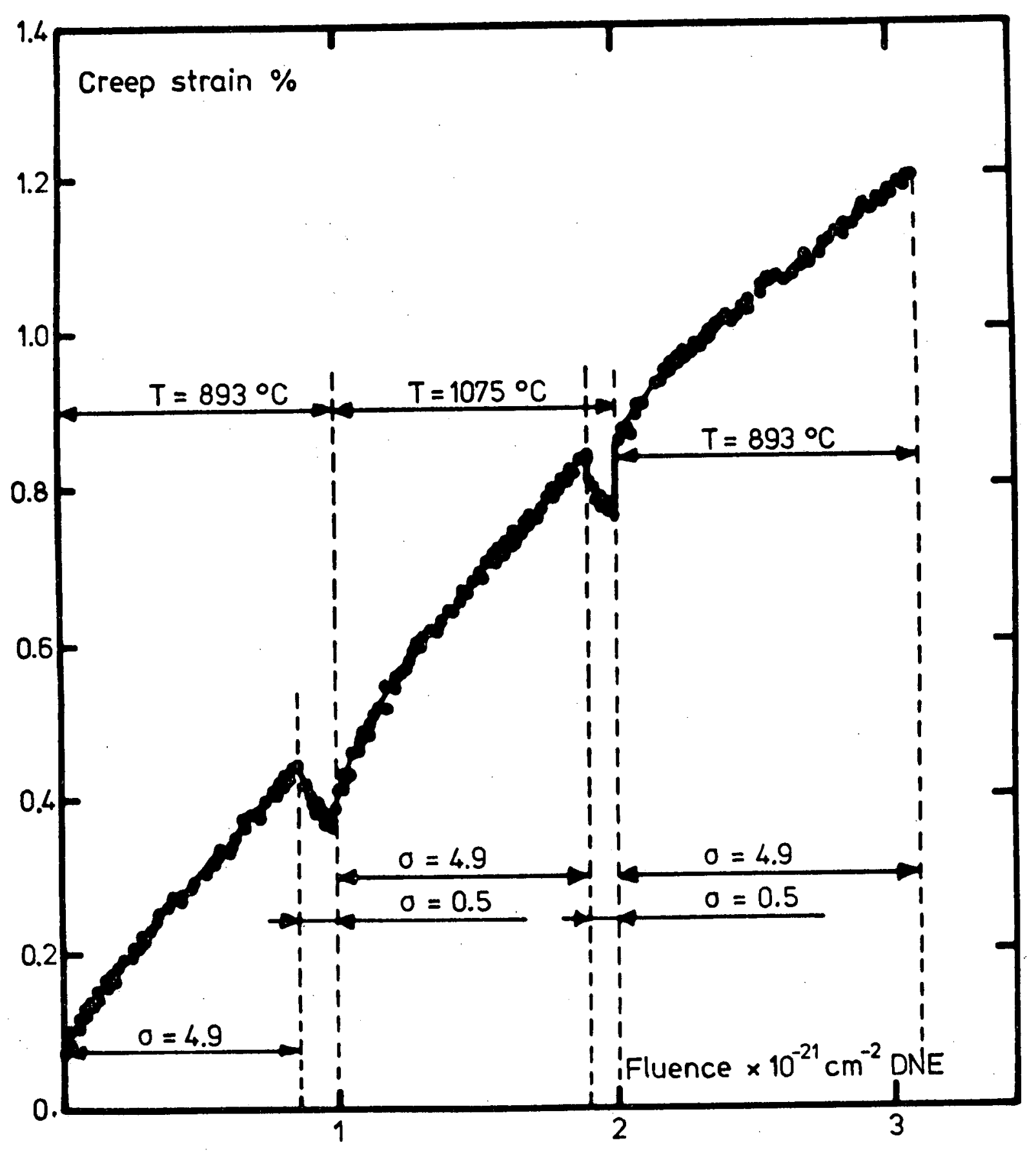

Fig. 10. Creep strain record of experiment FLACH 03 (from Ref. 19) 
TABLE 1

TRANSIENT CREEP CHARACTERISTICS

(from Ref. 19)

\begin{tabular}{|c|c|c|c|c|}
\hline & $\begin{array}{l}\text { FLACH-02(a) } \\
\text { AS2-M-500(b) }\end{array}$ & $\begin{array}{l}\text { FLACH-04(a) } \\
\text { AS2-F-500(b) }\end{array}$ & $\begin{array}{l}\text { FLACH-03 }(a) \\
P_{3} J_{H A N}(b)\end{array}$ & $\begin{array}{l}\text { ORPHEE-03(a) } \\
\text { P }_{3} \text { JHAN (b) }\end{array}$ \\
\hline $\begin{array}{l}\text { Ratio of total primary } \\
\text { creep strain to prece- } \\
\text { ding elastic strain }\end{array}$ & 0.74 & 1.17 & 1.45 & 1.03 \\
\hline $\begin{array}{l}\text { Ratio of total creep } \\
\text { recovery strain to } \\
\text { preceding primary } \\
\text { creep strain }\end{array}$ & 1.7 & 0.5 & 1.45 & 0.80 \\
\hline $\begin{array}{l}\text { Ratio of total recov- } \\
\text { ered strain to prece- } \\
\text { ding elastic and } \\
\text { primary creep strain }\end{array}$ & 1.28 & 0.70 & 0.76 & 0.80 \\
\hline $\begin{array}{l}\text { Primary creep expo- } \\
\text { nential coefficient } \\
\text { B in }\left(10^{19} \mathrm{~cm}^{-2} \text { DNE }\right)^{-1}\end{array}$ & 0.28 & 0.40 & 0.15 & 0.80 \\
\hline
\end{tabular}

(a) Experiment.

(b) Graphite grade. 
reencapsulated and the irradiation was continued under the designation D-166-01 (Refs. 21 and 22). The flux levels reported in Ref. 21 were subsequently revised ( $H$. J. Veringa, private communication). The revised fluxes are used here. In test R-135 (Ref. 20) the temperature was held in the range $820^{\circ}$ to $850^{\circ} \mathrm{C}$. The stress was set at $4.56 \mathrm{MPa}$ for the first step and was increased to $5.98 \mathrm{MPa}$ for the second step. For the third step the capsule was moved to a higher flux position; the stress setting remained at $5.98 \mathrm{MPa}$. The strain measuring system failed before the end of the test. The strain-versus-fluence history up to this point is shown in Fig. 11. In the follow-on experiment, D-166-01 (Ref. 21), the same specimen was reirradiated at $850^{\circ} \mathrm{C}$ under a stress of $6.0 \mathrm{MPa}$. The stress was removed for a period and reimposed for the remainder of the test. The recorded creep curve is shown in Fig. 12. The specimen was accidentally fractured during removal of the capsule shortly afterwards. In a follow-on experiment (D166-02), a fresh specimen of $\mathrm{H}-451$ was irradiated at $850^{\circ} \mathrm{C}$ under a load of 6 MPa to a fluence of about $2 \times 10^{21} \mathrm{n} / \mathrm{cm}^{2}$ (DNA) without interruption (M. R. Cundy, private communication). This test also ended with the accidental fracture of the specimen during a reactor shutdown.

The transient creep characteristics observed during the R-135/D-166 tests on $\mathrm{H}-451$ graphite were very similar to those found during the French tests on pitch coke graphites, except that in the initial loading of the R135 test both the total transient creep strain and the fluence required for saturation were unusually low (Fig. 11). This is believed to have been caused by the application of a large tensile preload ( $84 \%$ of the expected tensile strength) before irradiation, which caused a considerable "permanent set." If this permanent set was recovered early in irradiation, the apparent transient strain would be reduced (Ref. 21). The transient strains associated with the second loading in test $\mathrm{R}-135$, the start-up and second loading in test $\mathrm{D}-166-01$, and the start-up of test $\mathrm{D}-166-02$ ranged from 0.7 to 1.5 times the elastic strain, with an average of 0.9 . These ratios are in good agreement with the French tests (Table 1). The transient strain recovery at the unloading point in test D-166-01 (Fig. 12) continued for a longer period than in the French tests, suggesting that a portion of the 


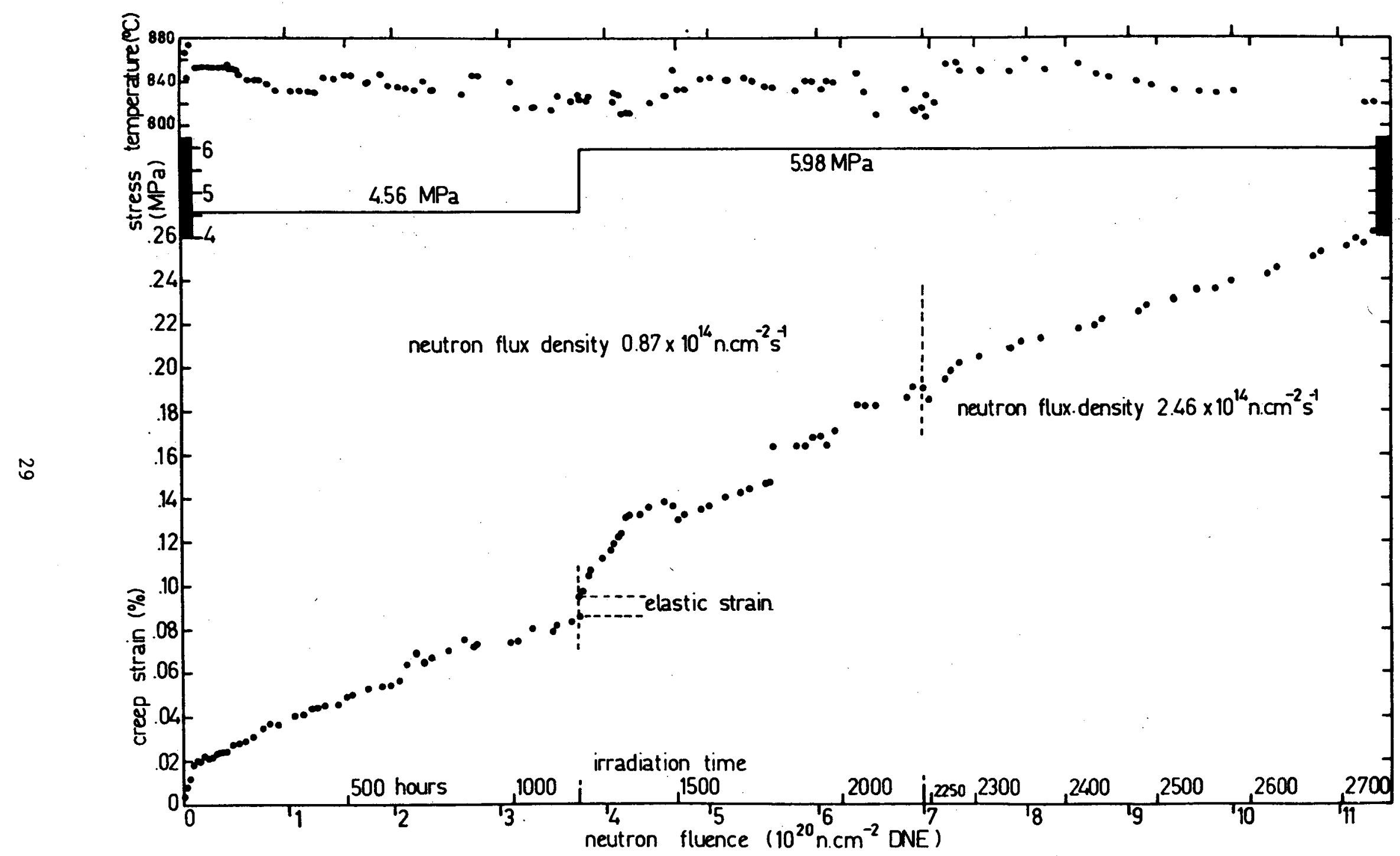

Fig. 11. Creep strain record of experiment R-135 (from Ref. 21; fluence values revised) 


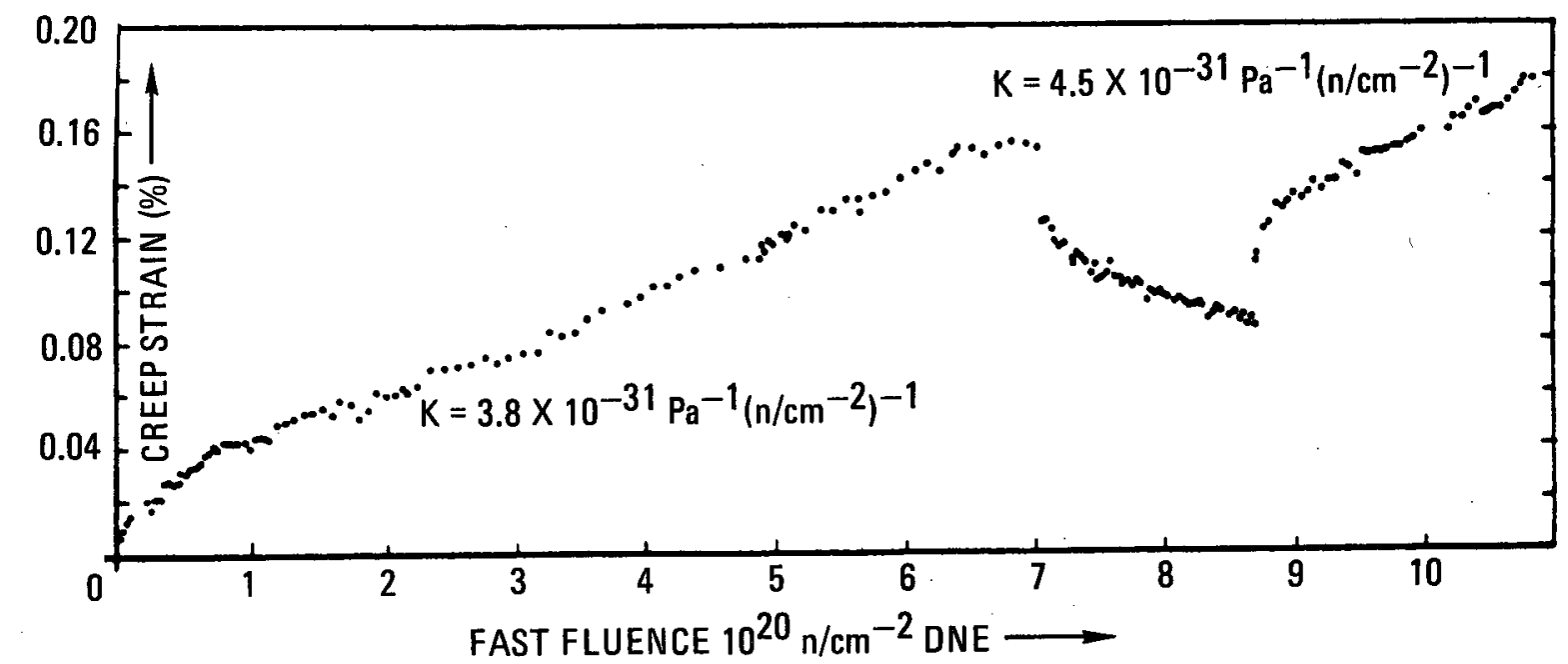

Fig. 12. Creep strain record of experiment D-166-01 at $850^{\circ} \mathrm{C}$ with tensile stress of $6 \mathrm{MPa}$ (from Ref. 22) 
steady-state creep may be recoverable in the highly strained $(0.56 \%)$ specimen. However, the recovered creep strain was again simflar in magnitude to the preceding transient creep strain. The transient creep exponential coefficients may be estimated graphically from Figs. 11 and 12; excluding the startup of test $\mathrm{R}-135$, the coefficients range from 0.3 to 1 $x 10^{-19}\left(\mathrm{n} / \mathrm{cm}^{2}, \mathrm{DNE}\right)^{-1}$, which is a little higher than the values from the French tests because of faster saturation after the second loadings.

Some useful confirmatory data on the total transient creep strain can be obtained from tests with out-of-reactor strain measurements, especially when the fluence increments are short. In reviewing earlier creep data obtained on a variety of graphites irradiated in the BR-2, Pluto, and Calder Hall reactors between $140^{\circ}$ and $650^{\circ} \mathrm{C}$, Kelly and Brocklehurst (Ref. 5) concluded that the ratio of total transient creep strain to elastic strain was close to 1 and that the exponential coefficient was about $0.4 \times 10^{-19}$ $\left(\mathrm{n} / \mathrm{cm}^{2}, \mathrm{DNE}\right)^{-1}$. No temperature dependence was seen. Reference 5 also includes some data on the recovery of strain in a tensile and a compressive specimen irradiated under a $6-\mathrm{MPa}$ stress to strains of about $0.7 \%$ and $1 \%$, respectively. During subsequent irradiation without stress, almost half the creep strain was eventually recovered, which is considerably greater than the transient creep strain. These data are discussed further in Subsection 5.4 .5

The experiments outlined above provide reasonably satisfactory verification of the basic points of the rheological model depicted in Fig. 1. They confirm the existence of a transient creep stage followed by steady-state creep, and show that the transient creep strain is slowly recovered when the load is removed. There are some indications that a portion of the steady-state creep strain in highly strained specimens is also recoverable, but there are not sufficient data to quantify this. The total transient creep strain is approximately equal to the elastic strain; thus, a in Eq. 1 is equal to 1.0 . Values for the transient creep exponential coefficient, $b$, fall in the range 0.15 to $1 \times 10^{-19}\left(\mathrm{n} / \mathrm{cm}^{2} \text {, DNE) }\right)^{-1}$, with a bestguess estimate of $0.3-0.4 \times 10^{-19}$. There is no evidence for a temperature 
dependence of $a$ or $b$; the data do not confirm an earlier indication that the transient creep strain might be higher at higher temperatures (Refs. 34 and 35 ).

\subsection{STEADY STATE CREEP}

\subsubsection{Dependence on Stress}

Early experiments on irradiation creep in graphite pointed to a linear dependence of creep rate on stress (Ref. 1), and the recent tests confirm this conclusion. The fully instrumented tests at Grenoble and Petten included step changes in the applied load. The steady-state creep rates before and after the load change were used to calculate the creep coefficient, $k(E q \cdot 1)$; a linear stress dependence requires that $k$ remain constant. When the tensile stress applied to the specimen in the $R-135$ test at Petten was increased from $4.56 \mathrm{MPa}$ to $5.98 \mathrm{MPa}$ (Fig. 11), the creep coefficient was essentially unchanged (Ref. 20) $\left[4.03 \times 10^{-31}\left(\mathrm{~Pa}-\mathrm{n} / \mathrm{cm}^{2}, \mathrm{DNE}\right)^{-1}\right.$, compared with $4.10 \times 10^{-31}$ before the change* ]. The values for $k$ for the various steps in the Grenoble experiments, taken from Ref. 19, are listed in Table 2. In the ORPHEE-03 experiment $k$ remained unaltered after an increase in stress from 2.5 to $4.5 \mathrm{MPa}$. However, the effect of the load changes in the FLACH-04 experiment was more erratic; as the stress was increased in steps from 2.8 to 4.9 to $7.0 \mathrm{MPA}, \mathrm{k}$ changed from 5.8 to 7.5 to $7.1 \times 10^{-31}$ $\left(\mathrm{Pa}-\mathrm{n} / \mathrm{cm}^{2}, \mathrm{DNE}\right)^{-1}$. These apparent differences were believed to have been caused by a discrepancy in free shrinkage rates between the stressed specimen and the reference specimen; no real departure from a linear stress dependence was postulated.

Controlled load experiments with out-of-reactor strain measurements can also be used to verify the linear stress dependence. Reference 5 includes a

\footnotetext{
* Revised calculations of the neutron flux during the two steps give values of 4.08 and $3.02 \times 10^{-31}\left(\mathrm{~Pa}-\mathrm{n} / \mathrm{cm}^{2}, \mathrm{DNE}\right)^{-1}$, respectively (M. R. Cundy, unpublished data).
} 
plot of the compressive creep strain rate at a fluence of about $10^{21} \mathrm{n} / \mathrm{cm}^{2}$ versus applied stress for creep experiments in the PLUTO and DRAGON reactors at $840^{\circ}$ and $1040^{\circ} \mathrm{C}$. The plot is shown in Fig. 13. The plots are essentially linear, except for some suggestion of an increased creep rate at the highest stress at $1040^{\circ} \mathrm{C}$. Such an increase in strain rate at high stresses would be predicted from Kelly's dislocation model for irradiation creep (Ref. 4). The compressive creep tests being conducted at ORNL include specimens under stresses of $13.8 \mathrm{MPa}$ and $20.7 \mathrm{MPa}$; no difference in creep coefficient has been found for these two sets of specimens (Refs. 25, 27, and 28).

The possibility of a higher steady-state creep coefficient for tensile loading compared with compressive loading was suggested by early experiments by Brocklehurst and Brown (Ref. 36), but the data were not conclusive. Recent experiments at Petten, utilizing controlled tensile and compressive loads with out-of-reactor strain measurement (Refs. 30 through 33), show a clear difference in creep rates for tension and compression in specimens of Sigri ATR-2E graphite tested at $500^{\circ} \mathrm{C}$. The data are shown in Fig. 14, taken from Ref. 33. At a given fluence, the creep coefficient for compressive creep is $20 \%$ to $30 \%$ lower than the coefficient for tensile creep.

\subsubsection{Dependence on Material Properties}

Early irradiation creep experiments on grades of graphite with a pronounced preferred orientation showed a higher steady-state creep coefficient in the against-grain direction than in the with-grain direction. This orientation dependence is consistent with Kelly and Brocklehurst's analysis of irradiation creep (Ref. 3), which predicts that the steady-state creep coefficient should be proportional to $\mathrm{C}_{44} / \mathrm{E}(\mathrm{Eq} \cdot 2)$, where $\mathrm{C}_{44}$ is the single crystal elastic constant for basal shear and $E$ is Young's modulus. At low neutron fluences dislocation pinning causes $\mathrm{C}_{44}$ and $\mathrm{E}$ to rise rapidly to a plateau, with their ratio remaining constant. Later in irradiation, structural changes cause a secondary increase in $\mathrm{E}$, this time without a 


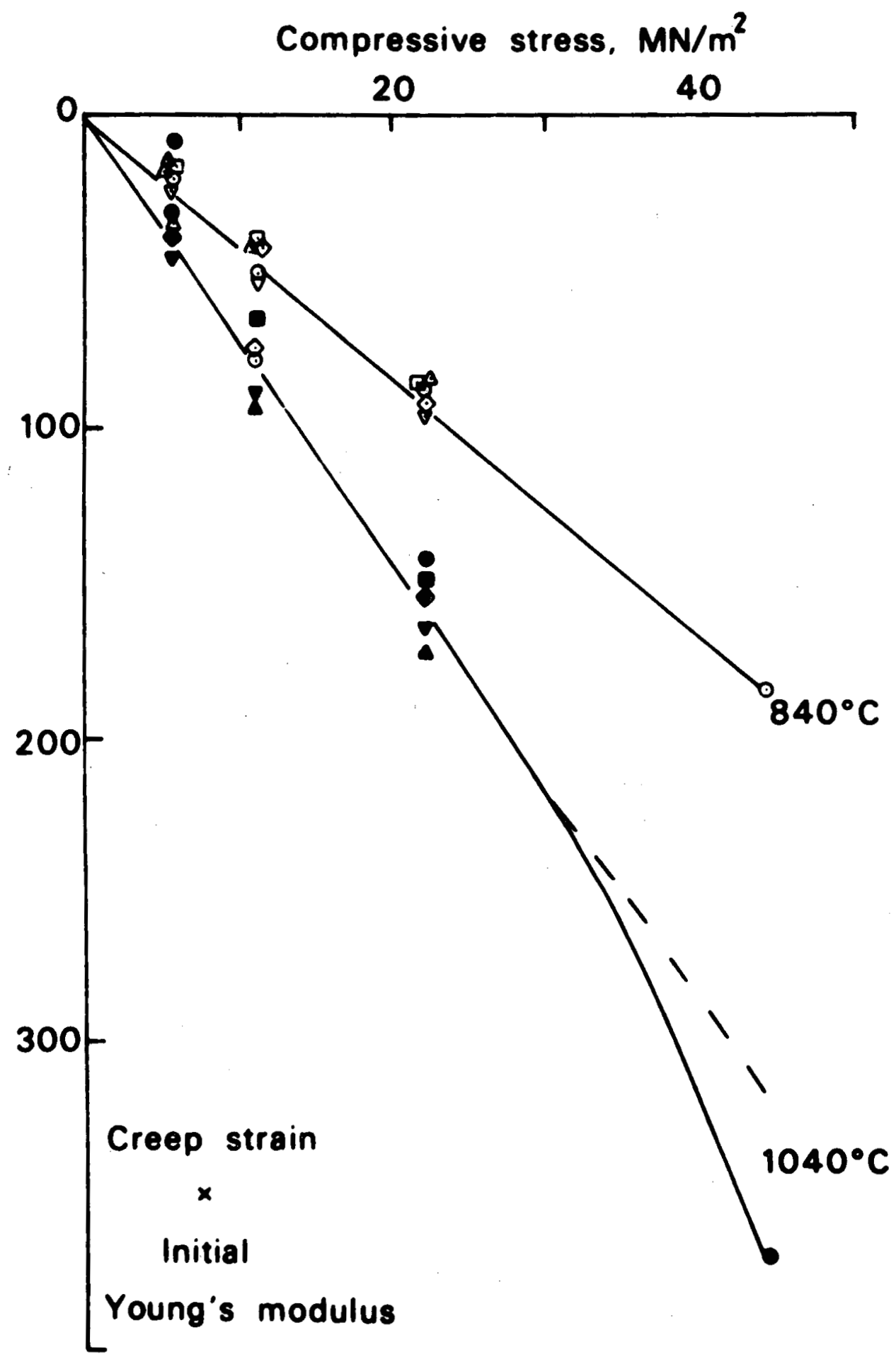

Fig. 13. Creep strain as a function of compressive stress for different graphites at a fluence of approximately $10^{21} \mathrm{n} / \mathrm{cm}^{2}$ (DNE) (from Ref. 5) 


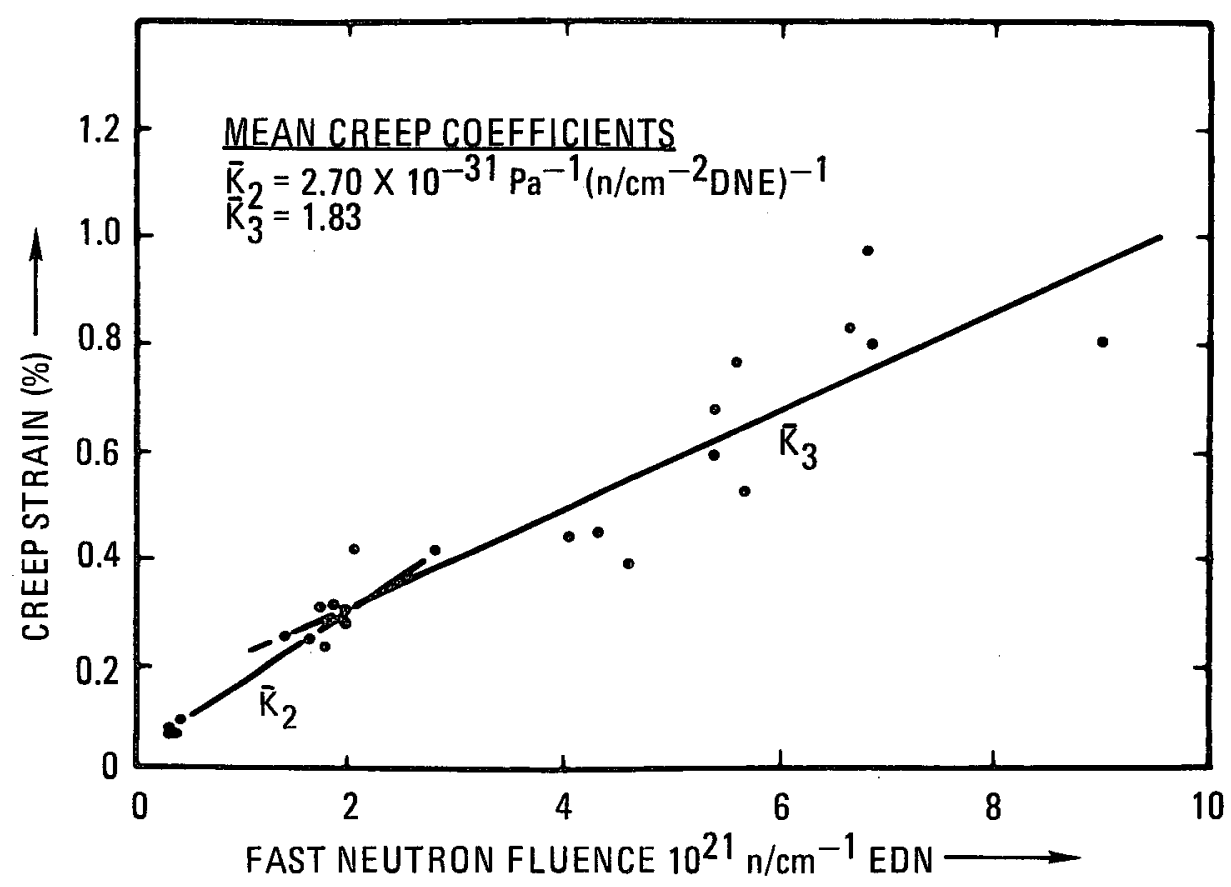

(a)

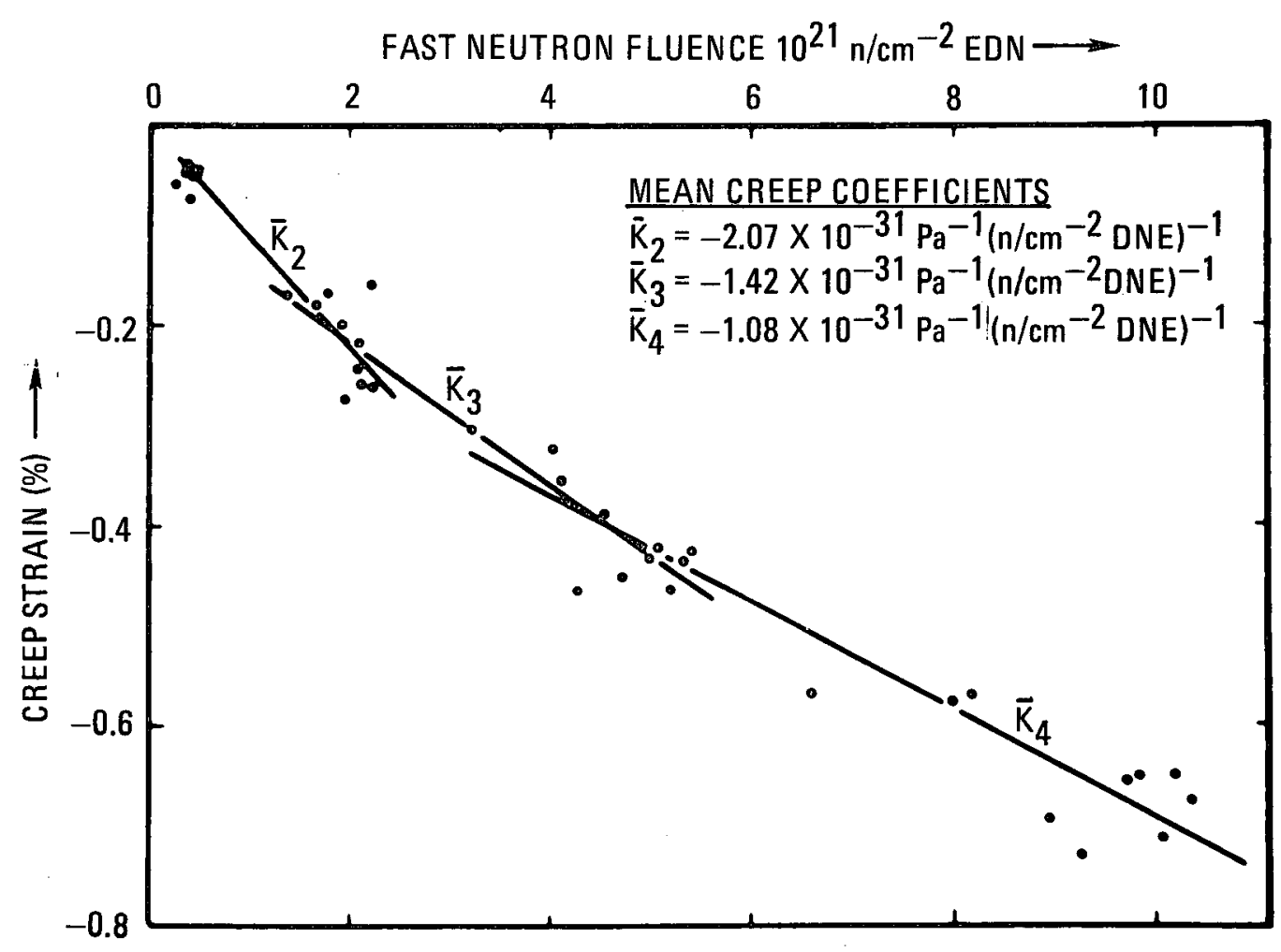

(b)

Fig. 14. Creep strain as a function of neutron fluence for ATR-2E graphite (axial orientation) at $500^{\circ} \mathrm{C}:$ (a) tension, (b) compression (from Ref. 33) 
concurrent change in $\mathrm{C}_{44}$. Oxidation also causes drastic changes in $\mathrm{E}$ due to structural modifications. The implications are that the creep coefficient should be inversely proportional to the unirradiated. Young's modulus for any grade or orientation of graphite, and the same relationship should hold for oxidized graphite. High fluence irradiation should result in a declining creep coefficient until porosity generation reduces Young's modulus, at which stage the creep coefficient should increase.

The inverse dependence of the creep coefficient, $k$, on unirradiated Young's modulus, $E_{O}$, is well supported by experimental data. This dependence is illustrated by the Petten data obtained by the restrained shrinkage method (Ref. 12), which covers a wide range of graphite types including both vith-grain and against-grain orientations. Figure 15(a) (from Ref. 12) shows the creep coefficient, $k$, plotted as a function of temperature for all graphite types for neutron fluxes in the range 0.2 to $2.5 \times 10^{14} \mathrm{n} / \mathrm{cm}^{2}$ ). In Fig. 15(b) the same data are replotted using $\mathrm{k} \times \mathrm{E}_{O}$ as the ordinate. The scatter is greatly reduced, supporting an inverse relationship between $k$ and $E_{O}$.

This relationship also holds for graphite whose Young's modulus has been reduced by oxidation (Refs. 3 and 5 ). Data reported in Ref. 5 show very different creep rates at $300^{\circ}$ to $650^{\circ} \mathrm{C}$ for isotropic graphite, the same material prexoidized to $25 \%$ to $28 \%$ weight 1 oss, anisotropic PGA graphite both parallel and perpencicular to extrusion, and highly oriented pyrolytic graphite. However, wher the same data were plotted in terms of creep strain per unit initial elastic strain $\left(\varepsilon \mathrm{E}_{o} / \sigma\right)$, the scatter was much reduced.

Similar conclusions may be drawn from the Oak Ridge constant load compressive creep tests at $600^{\circ}$ and $900^{\circ} \mathrm{C}$ (Refs. 25, 27, and 28). The tests included an anisotropic graphite $(\mathrm{H}-327)$ in both parallel and perpendicular direction, and two isotropic graphites ( $H-451$ and $A X F-8 Q$ ). Values for the initial Young's modulus, ranged over a factor of 2 . The measured steadystate creep coefficients increased with decreasing Young's modulus, and the data were in good agreement with the predicted inverse relationship. 


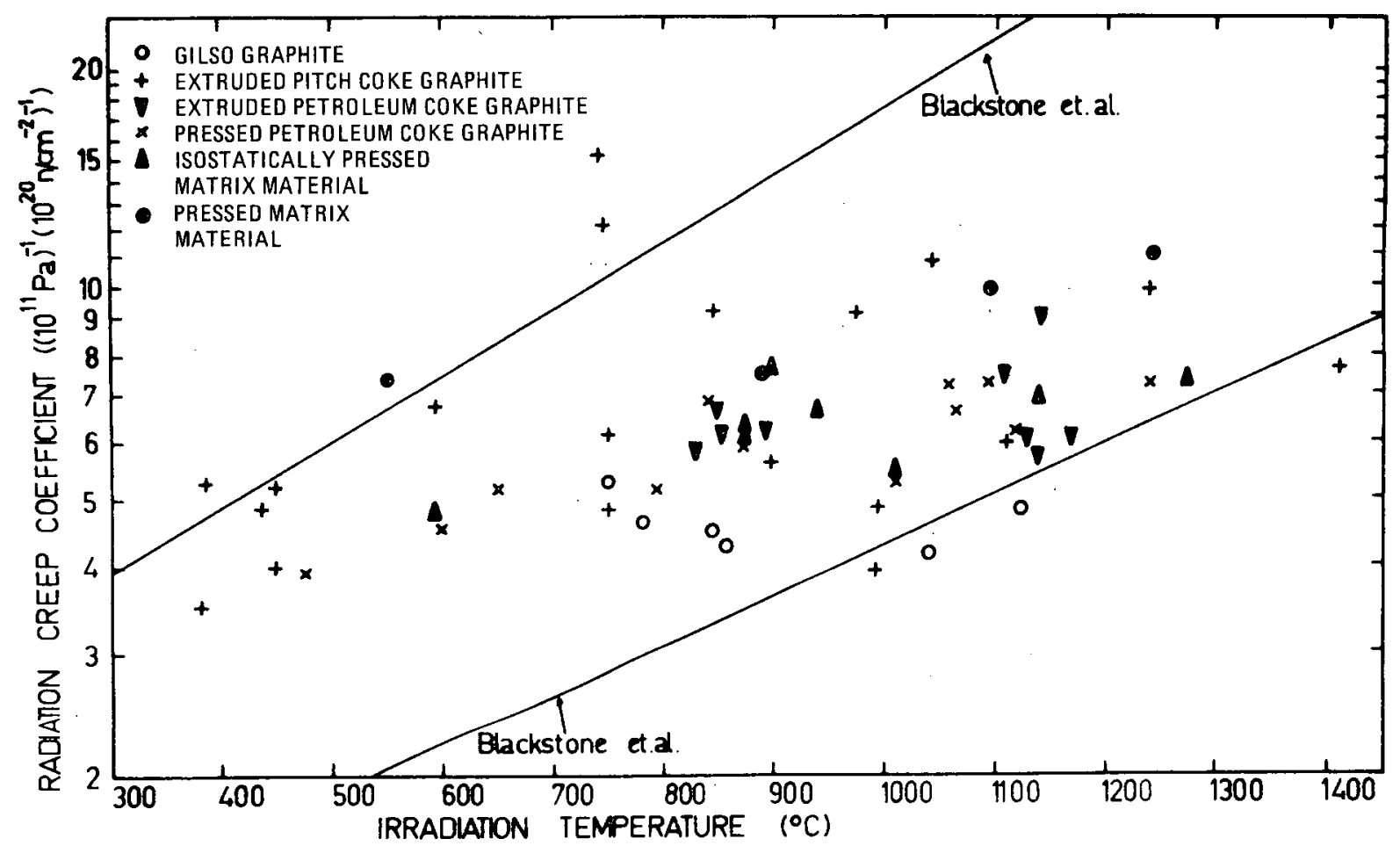

(a)

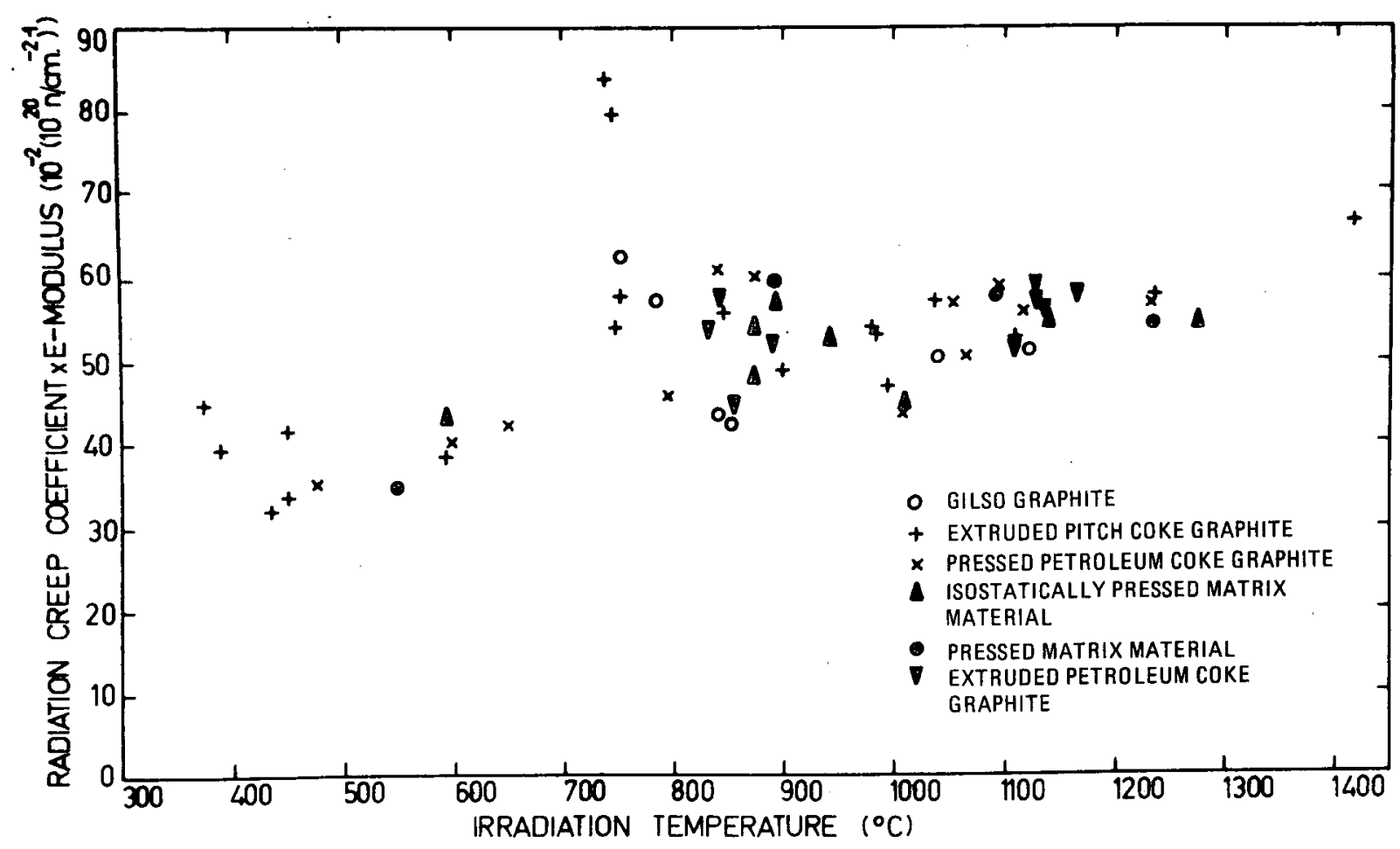

(b)

Fig. 15. Steady-state irradiation creep data from restrained shrinkage tests: (a) creep coefficient as a function of temperature; (b) creep coefficient multiplied by initial Young's modulus as a function of temperature (from Ref. 12) 
Changes in the creep coefficient at high fluences are discussed in Subsection 5.2 .4 .

\subsubsection{Dependence on Temperature and Neutron F1ux}

Much effort has been expended at several laboratories to characterize the dependence of the steady-state creep coefficient on temperature and neutron flux. The bulk of the data were derived from isothermal restrained shrinkage or controlled load tests with out-of-reactor strain measurements. Additional data were obtained from tests with continuous strain registration where a step change in temperature was imposed, or where the neutron flux was changed by moving the entire capsule assembly to a different position in the test reactor.

The restrained shrinkage tests conducted at Petten (Refs. 11 through 15) covered a wide temperature range $\left(350^{\circ}\right.$ to $\left.1400^{\circ} \mathrm{C}\right)$ and flux range $(0.24$ to $2.4 \times 10^{14} \mathrm{n} / \mathrm{cm}^{2}-\mathrm{s}$, DNE). A progressive increase in creep coefficient with temperature is clearly apparent (Fig. 15). Veringa and Blackstone (Refs. 12 and 13) noted that if the neutron flux is taken into account, coefficients derived from specimens irradiated at a low neutron flux tend to fall high, while data from specimens irradiated in a high flux tend to fall low. This trend was most noticeable if early UKAEA high flux data from restrained shrinkage tests in the Dounreay fast reactor (Ref. 37) and lowflux data from tensile strings for the Dragon reactor (Refs. 34 and 35) were included. The data are shown in Fig. 16. Veringa and Blackstone systematized the data by assuming that the product of the creep coefficient, $k$, and Young's modulus, E, has a flux-dependent part and a flux-independent part:

$$
k E=\frac{f(T)}{\phi}+g(T),
$$

where $\phi$ is the neutron flux and $f(T)$ and $g(T)$ are functions of the irradiation temperature, T. Lines based on Eq. 4, assuming that $f(T)$ and $g(T)$ are linear functions, are shown in Fig. 16. It was suggested that the first 


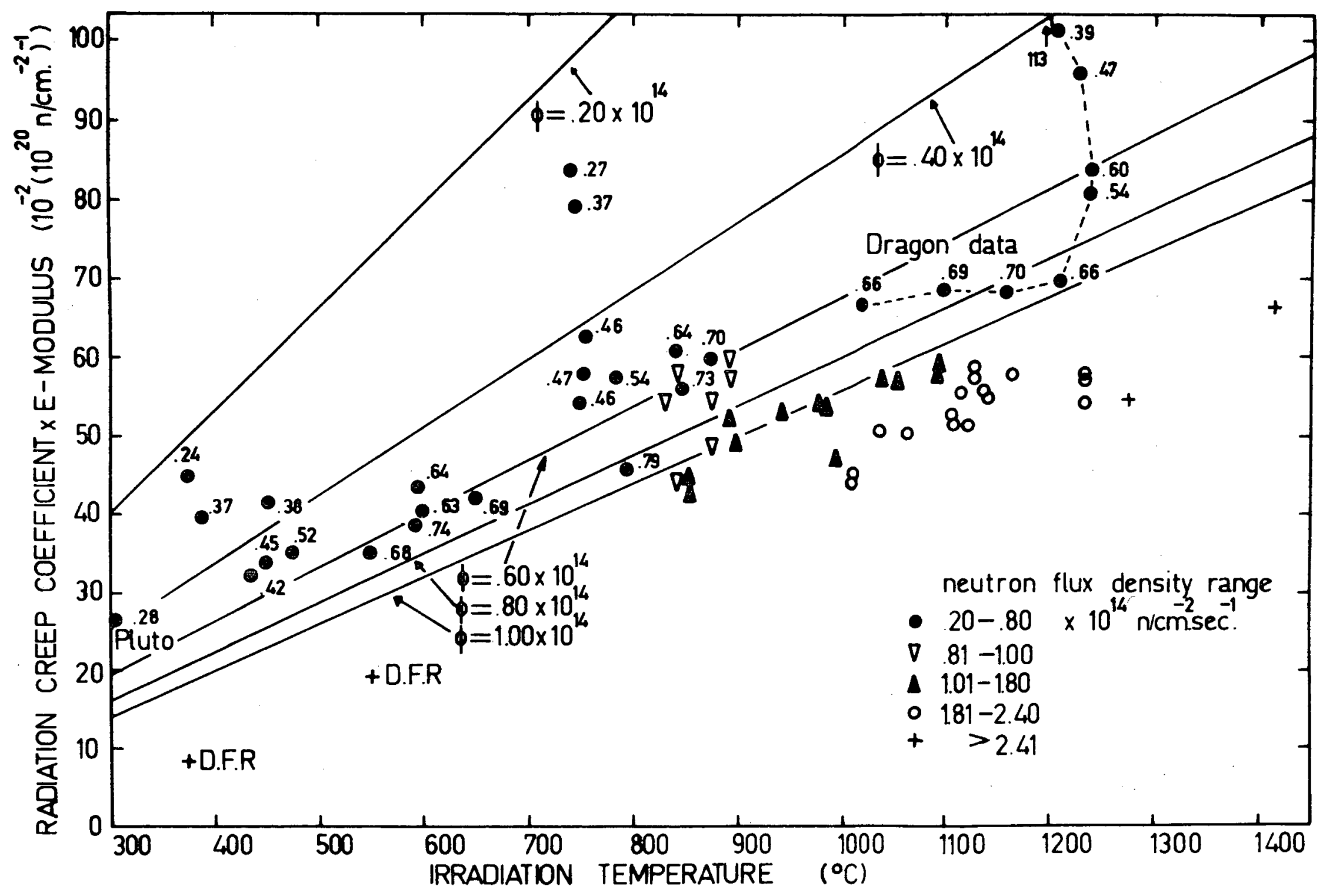

Fig. 16. Steady-state irradiation creep data from restrained shrinkage tests: creep coefficient multiplied by initial Young's modulus for different flux ranges as a function of temperature (from Ref. 12) 
term in Eq. 4 might correspond to the Kelly-Foreman creep mechanism if the dislocation pinning point density is assumed to be proportional to the flux, and the second term might correspond to Roberts-Cottrell creep (Section 3 ). The flux-dependent lines in Fig. 16 are certainly a plausible representation of the data. It is worth noting that the early Dounreay fast reactor points (Ref. 37) may not be directly comparable to more recent measurements because of the high neutron fluence (see Subsection 5.2.4) and the unsophisticated technique.

To clarify the temperature and flux dependence of the creep coefficient, step changes in both temperature and flux were included in the continuous-registration test series at Grenoble (Refs. 16 through 19). Table 2 summarizes the results. In the FLACH-02 experiment, when the temperature was changed from $893^{\circ}$ to $1088^{\circ} \mathrm{C}$ and back to $893^{\circ} \mathrm{C}$, the creep coefficient changed from 5.4 to 6.9 to $5.3 \times 10^{-31}\left(\mathrm{~Pa}-\mathrm{n} / \mathrm{cm}^{2}, \mathrm{DNE}\right)^{-1}$. These changes were about as expected. A similar series of step temperature changes during the FLACH-03 experiment produced less consistent results; the creep coefficient changed from 8.3 to 8.0 to $5.6 \times 10^{-31}\left(\mathrm{~Pa}-\mathrm{n} / \mathrm{cm}^{2}, \mathrm{DNE}\right)^{-1}$. The apparent inconsistency was attributed to differences in the shrinkage curves of the tensile specimen and its unstressed companion (Ref, 19). When the neutron flux in the FLACH-02 experiment was reduced from 1.72 to $0.60 \mathrm{x}$ $10^{14} \mathrm{n} /\left(\mathrm{cm}^{2}-\mathrm{s}\right)$ (DNE), the creep coefficient increased from 5.3 to 8.6 $x 10^{-31}\left(\mathrm{~Pa}-\mathrm{n} / \mathrm{cm}^{2}, \mathrm{DNE}\right)^{-1}$. However, a similar step change in the FLACH-04 test produced the opposite result: the creep coefficient decreased from 7.1 to $\left.5.6 \times 10^{-31}(\mathrm{~Pa}-\mathrm{n}) / \mathrm{cm}^{2}, \mathrm{DNE}\right)^{-1}$. The flux change was created by moving the experimental rig to a different test hole in the reactor, which may have disturbed the sensitive in-reactor measurement system. The authors therefore judged that the experiment did not allow any conclusions either for or against the existence of a flux-dependency of the creep coefficient.

The continuous-registration creep tests on $\mathrm{H}-451$ graphite conducted at Petten (Refs. 21 and 22) included a step change in flux. The first two steps of the R-135 experiment (Fig. 11) were conducted at a flux of 0.87 $x 10^{14} \mathrm{n} / \mathrm{cm}^{2}-\mathrm{s}$ (DNE), and the rig was moved to a high flux position $(2.46$ 
TABLE 2

STEADY-STATE CREEP COEFFICIENTS FROM CEA/KFA CONTINUOUSLY MEASURED CREEP TESTS (from Ref. 19)

\begin{tabular}{|c|c|c|c|c|c|c|c|}
\hline Experiment & $\begin{array}{l}\text { Graphite } \\
\text { Grade }\end{array}$ & Step & $\begin{array}{c}\text { Temperature } \\
\left({ }^{\circ} \mathrm{C}\right)\end{array}$ & $\begin{array}{l}\text { Stress } \\
(\mathrm{MPa})\end{array}$ & $\begin{array}{c}\text { Neutron F1ux } \\
\left(10^{14} \mathrm{n} / \mathrm{cm}^{2}-\mathrm{s}, \text { DNE }\right)\end{array}$ & $\begin{array}{c}\text { Steady-State Creep } \\
\text { Coefficlent, } \mathrm{k} \\
{\left[10^{-31}\left(\mathrm{~Pa} \mathrm{n} / \mathrm{cm}^{2}, \mathrm{DNE}\right)^{-1}\right]}\end{array}$ & $\begin{array}{c}\mathrm{k} x \text { Young's } \\
\text { Modulus } \\
{\left[10^{-21}\left(\mathrm{n} / \mathrm{cm}^{2}, \mathrm{DNE}\right)^{-1}\right]}\end{array}$ \\
\hline FLACH-02 & AS2-M-500 & $\begin{array}{l}1 \\
2 \\
3 \\
4\end{array}$ & $\begin{array}{r}893 \\
1088 \\
893 \\
845\end{array}$ & $\begin{array}{l}4.9 \\
4.9 \\
5.0 \\
5.0\end{array}$ & $\begin{array}{l}1.72 \\
1.72 \\
1.72 \\
0.60\end{array}$ & $\begin{array}{l}5.40 \pm 0.07 \\
6.93 \pm 0.09 \\
5.33 \pm 0.09 \\
8.64 \pm 0.12\end{array}$ & $\begin{array}{l}4.50 \\
5.78 \\
4.45 \\
7.21\end{array}$ \\
\hline FLACH-04 & AS2-F-500 & $\begin{array}{l}1 \\
2 \\
3 \\
4\end{array}$ & $\begin{array}{l}894 \\
893 \\
895 \\
874\end{array}$ & $\begin{array}{l}2.8 \\
4.9 \\
7.0 \\
7.0\end{array}$ & $\begin{array}{l}1.59 \\
1.59 \\
1.59 \\
0.65\end{array}$ & $\begin{array}{l}5.84 \pm 0.19 \\
7.52 \pm 0.10 \\
7.06 \pm 0.10 \\
5.62 \pm 0.11\end{array}$ & $\begin{array}{l}4.65 \\
5.99 \\
5.62 \\
4.47\end{array}$ \\
\hline FLACH-03 & $\mathrm{P}_{3} \mathrm{JHAN}$ & $\begin{array}{l}1 \\
2 \\
3\end{array}$ & $\begin{array}{r}893 \\
1075 \\
893\end{array}$ & $\begin{array}{l}4.9 \\
4.9 \\
4.9\end{array}$ & $\begin{array}{l}1.85 \\
1.85 \\
1.85\end{array}$ & $\begin{array}{l}8.26 \pm 0.10 \\
7.99 \pm 0.15 \\
5.57 \pm 0.09\end{array}$ & $\begin{array}{l}5.88 \\
5.69 \\
3.97\end{array}$ \\
\hline ORPHEE-03 & $\mathrm{P}_{3}$ JHAN & $\begin{array}{l}1 \\
2\end{array}$ & $\begin{array}{l}945 \\
945\end{array}$ & $\begin{array}{l}2.5 \\
4.5\end{array}$ & $\begin{array}{l}1.45 \\
1.45\end{array}$ & $\begin{array}{l}8.85 \pm 0.30 \\
8.85 \pm 0.16\end{array}$ & $\begin{array}{l}6.20 \\
6.20\end{array}$ \\
\hline
\end{tabular}


$x 10^{14} \mathrm{n} / \mathrm{cm}^{2}-\mathrm{s}$, DNE) for the third step. The initial analysis indicated that the creep coefficient fell from 4.03 to $2.46 \times 10^{-31}\left(\mathrm{~Pa}-\mathrm{n} / \mathrm{cm}^{2} \text {, DNE }\right)^{-1}$ between the second and third step, but these values were later revised to 3.02 and $2.53 \times 10^{-31}$, respectively (M. R. Cundy, unpublished data). When the specimen was reirradiated in test $\mathrm{D}-166$ in a high flux position (about 2 $x 10^{14} \mathrm{n} / \mathrm{cm}^{2}-\mathrm{s}$, DNE) the creep coefficient returned to a higher value [3.8 $\left.\times 10^{-31}(\mathrm{~Pa}-\mathrm{n}) / \mathrm{cm}^{2}, \mathrm{DNE}\right)^{-1}$, later revised to $4.04 \times 10^{-31} \mathrm{]}$. Thus the Petten experiments, like the Grenoble experiments, failed to confirm the earlier indication of a systematic effect of flux on the creep coefficient.

In their review of UKAEA creep work, Kelly and Brocklehurst (Ref. 5) showed a composite plot of the steady-state creep coefficients from controlled stress tests in the $B R-2$, Pluto, and Dragon reactors as a function of temperature. The data indicate no significant temperature dependence between $300^{\circ}$ and $700^{\circ} \mathrm{C}$, then a progressive accelerating increase with temperature up to $1200^{\circ} \mathrm{C}$. No separate effect of flux was postulated.

The OC-series of compressive creep tests at ORNL (Refs. 25, 27, and 28) show creep coefficients at $900^{\circ} \mathrm{C}$ to be 1.5 to 2 times higher than at $600^{\circ} \mathrm{C}$. The authors suggested that the temperature dependence of the creep coefficient may be explained by the Roberts-Cottre11 model (Eq. 3). If the crystallite yield stress, $Y$, is independent of temperature, the creep coefficient should have the same temperature dependence as the differential crystallite dimensional change rate, $\left[\left(1 / x_{c} \cdot d_{c} / d \gamma\right)-\left(1 / x_{a} \cdot d x_{a} / d \gamma\right)\right]$. This quantity is known to decrease with irradiation temperature up to about $400^{\circ} \mathrm{C}$, pass through a shallow minimum, then increase rapidly. Early measurements for the creep coefficients for oriented graphite grades are in reasonable agreement with the predicted temperature dependence (Ref. 28).

The Petten controlled-load tests on ATR-2E graphite (Refs. 30 through 33) showed a creep coefficient at $300^{\circ} \mathrm{C}$ about $15 \%$ higher than at $500^{\circ} \mathrm{C}$. Early data appeared to show a trend toward a higher creep coefficient at low flux levels (Ref. 30), but later tests did not confirm this trend (Ref. 33). 
To summarize, the tests reviewed above did not confirm earlier indications of higher creep coefficients at low fluxes. In spite of the increased complexity of the test facilities and more sophisticated data analysis, the more recent tests have also done little to improve the knowledge of the temperature dependence of the creep coefficient. Figure 17 is a plot of the product of the steady-state creep coefficient and unirradiated Young's modulus $\left(\mathrm{kE}_{\mathrm{o}}\right)$ versus irradiation temperature for the tests reviewed in this section, restricting the data to points obtained at fluences below 3 $x 10^{21} \mathrm{n} / \mathrm{cm}^{2}$ (DNE) because of the trend towards lower creep coefficients at high fluences (see Subsection 5.2.4). The fluxes are indicated for each point. Figure 17 also includes the flux-dependent lines for $0.6,1.0$ and $3.0 \times 10^{14} \mathrm{n} / \mathrm{cm}^{2}-\mathrm{s}$ (DNE) from Veringa's analysis of the Petten restrained shrinkage data (Ref. 12 and 13); the empirical temperature dependence line from Kelly and Brocklehurst's review of UKAEA data (Ref. 5); and the temperature dependence line based on Roberts-Cottrell creep proposed by Kennedy (Ref. 27). None of the lines represent all the data points to within the claimed $\pm 25 \%$ accuracy; and the scatter in the data is such that it is not possible to say which line best conforms to the new measurements. The high scatter in the $830^{\circ}$ to $900^{\circ} \mathrm{C}$ temperature range of the Grenoble and Petten continuous-registration experiments coincides with a steep slope in the ORNL and UKAEA temperature dependence curves, suggesting that a part of the discrepancy could result from deviations between the recorded temperature and the actual specimen temperature. Since the thermocouples in the experiments are located in a container drum separated by a gas gap from the specimen and gamma heating in the specimen generates much of the heat, such deviations can be considerable.

The data points in Fig. 17 for $\mathrm{H}-451$ graphite, the reference grade for the fuel elements in the US HTGR program, appear to fall closer to the UKAEA line than the other lines shown, and this line therefore seems to be more 


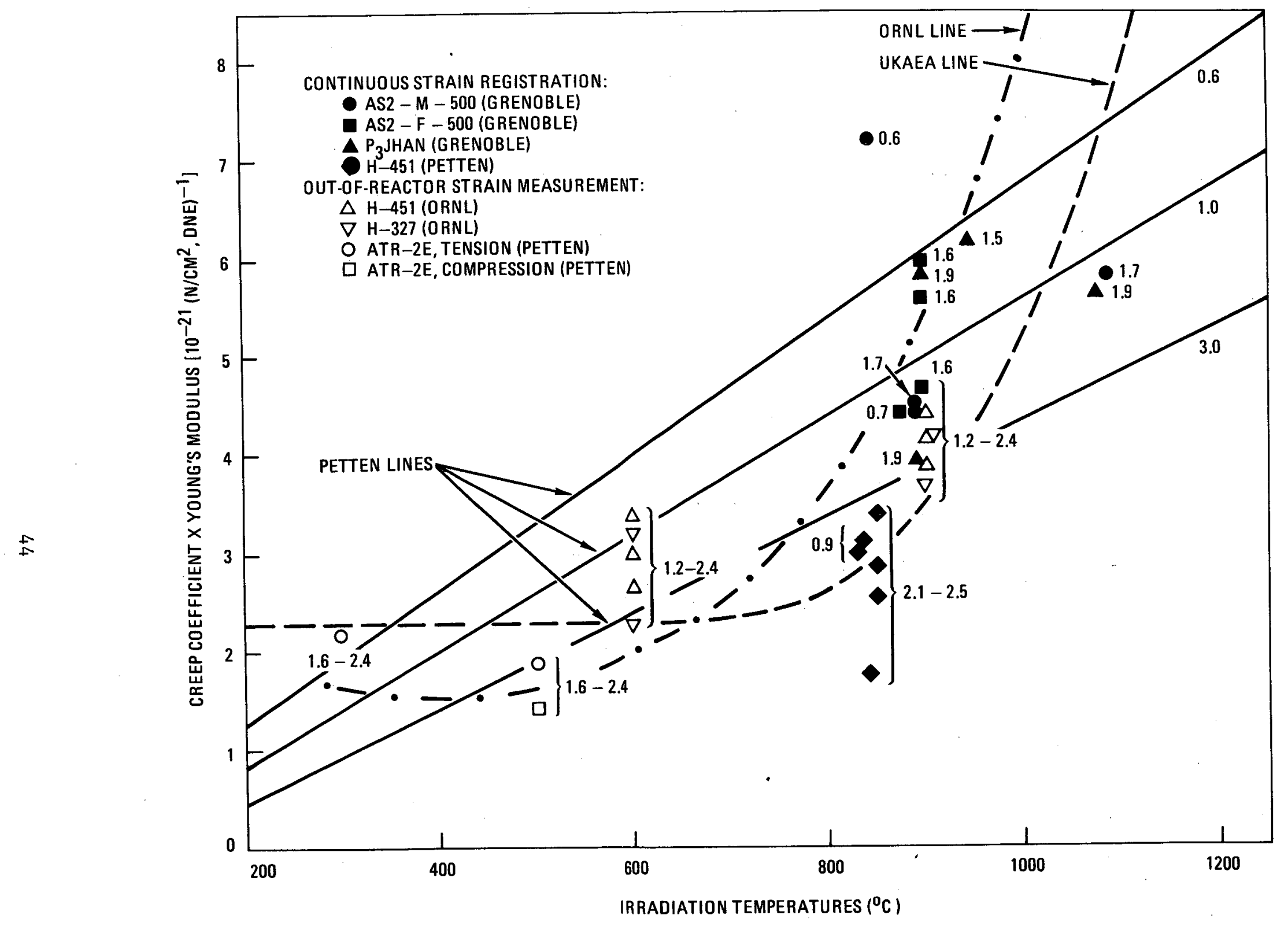

Fig. 17. Composite plot of creep coefficient multiplied by initial Young's modulus as a function of temperatures 
appropriate for design purposes. The following equation represents the UKAEA line:

$$
\left.\begin{array}{l}
\mathrm{T}<650^{\circ} \mathrm{C}: \mathrm{kE}_{\mathrm{o}}=2.3 \times 10^{-21}, \\
\mathrm{~T} \geq 650^{\circ} \mathrm{C}: \mathrm{kE}_{\mathrm{O}}=2.3 \times 10^{-21}+7 \times 10^{-28}(\mathrm{~T}-650)^{2.6},
\end{array}\right\}
$$

where $\mathrm{T}$ is the temperature in ${ }^{\circ} \mathrm{C}$ and $\mathrm{kE}_{\mathrm{O}}$ is in the units $\left(\mathrm{n} / \mathrm{cm}^{2}, \mathrm{DNE}\right)^{-1}$.

\subsubsection{Dependence on Neutron Fluence}

As discussed in Subsection 5.2.2, Kelly and Brocklehurst's analysis of irradiation creep predicts that the steady-state creep coefficient should decline as Young's modulus undergoes its secondary increase at fluences

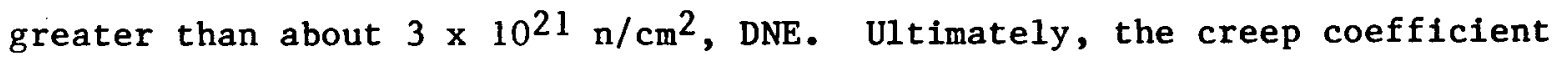
should rise again as porosity generation lowers Young's modulus. Kelly and Brocklehurst (Ref. 3) divide the irradiation-induced change in Young's modulus, $E / E_{O}$, into components, one due to dislocation pinning and one due to structural changes:

$$
\frac{E}{E_{0}}=\left(\frac{E}{E_{o}}\right)_{P} \times\left(\frac{E}{E_{O}}\right)_{S}
$$

Since the component due to pinning $\left(\mathrm{E} / \mathrm{E}_{\mathrm{O}}\right)_{\mathrm{P}}$, is caused by a parallel change in the crystal elastic constant, $\mathrm{C}_{44}$, it follows from $\mathrm{Eq}$. 2 that the creep coefficient should be inversely proportional to $\left(E / E_{O}\right)_{S} \cdot\left(E / E_{O}\right)_{P}$ reaches saturation after a low fluence and is assumed to remain unchanged thereafter. $\left(E / E_{O}\right)_{S}$ is therefore equal to $E / E^{*}$, where $E^{*}$ is the plateau value of Young's modulus when dislocation pinning is saturated. The creep coefficient, $k$, at a fluence $\gamma$ should therefore be given by:

$$
k(\gamma)=k^{*}\left[\frac{E^{*}}{E(\gamma)}\right]=k^{*} s(\gamma),
$$


where $\mathrm{k}^{*}$ is the creep coefficient in the plateau region (fluence less than about $\left.3 \times 10^{21} \mathrm{n} / \mathrm{cm}^{2}, E D N\right)$. S is the fluence-dependent structural factor.

Kelly and Brocklehurst (Ref. 3) used a plot of $\left(E / E_{O}\right)_{S}$ versus fluence to predict creep strains in graphite specimens previously irradiated to fluences of about $1.5 \times 10^{22} \mathrm{n} / \mathrm{cm}^{2}$. The measured creep strains were less than would have been predicted using the plateau value for the creep coefficient, $\mathrm{k}^{*}$, but somewhat greater than would have been predicted from Eq. 7 . The controlled load tests conducted at Petten on ATR-2E graphite (Refs. 32 and 33) show a progressive decline in the creep coefficient with fluence, both in tension and compression (see Fig. 14). The coefficients at $500^{\circ} \mathrm{C}$ divided by the plateau value at $0.8-1.4 \times 10^{21} \mathrm{n} / \mathrm{cm}^{2}\left(\mathrm{k}^{*}\right)$ are plotted against fluence in Fig. 18, taken from Ref. 33. Figure 18 also shows the structural factor, $S(\gamma)$, calculated from Eq. 7 , and the high fluence points from Ref. 3. The reduction in creep coefficient at high fluences measured in the Petten tests is somewhat more than predicted, in contrast to Kel1y and Brocklehurst's observations (Ref. 3).

The continuously monitored tensile creep experiments at Grenoble and Petten (Refs. 19 and 22) extended to fluences of about 3 and $3.5 \times 10^{21}$ $\mathrm{n} / \mathrm{cm}^{2}$, DNE, respectively, but neither test series showed a clear reduction in creep coefficient with fluence. However, the ORNL compressive creep tests on $\mathrm{H}-451$ graphite at $900^{\circ} \mathrm{C}$ (Ref. 28) show a trend toward a lower creep coefficient at higher fluences; at a fluence of about $1.7 \times 10^{21} \mathrm{n} / \mathrm{cm}^{2}$, DNE, and a compressive creep strain of $1.5 \%$ to $2 \%$, the coefficient was about $30 \%$ lower than the initial value. At this fluence and temperature Young's modulus would not be expected to have increased above the plateau level, and no reduction in creep coefficient would have been predicted by Eq. 7 . The compressive creep strain in this experiment was higher than in the other work described above, and it is possible that the greater-than-expected reduction in creep coefficient was caused by the specimens approaching a compressive strain limit. Gray's compressive creep tests (Ref. 38) had earlier suggested that isotropic graphites approach a compressive strain limit at $2 \%$ to $3 \%$ strain. 


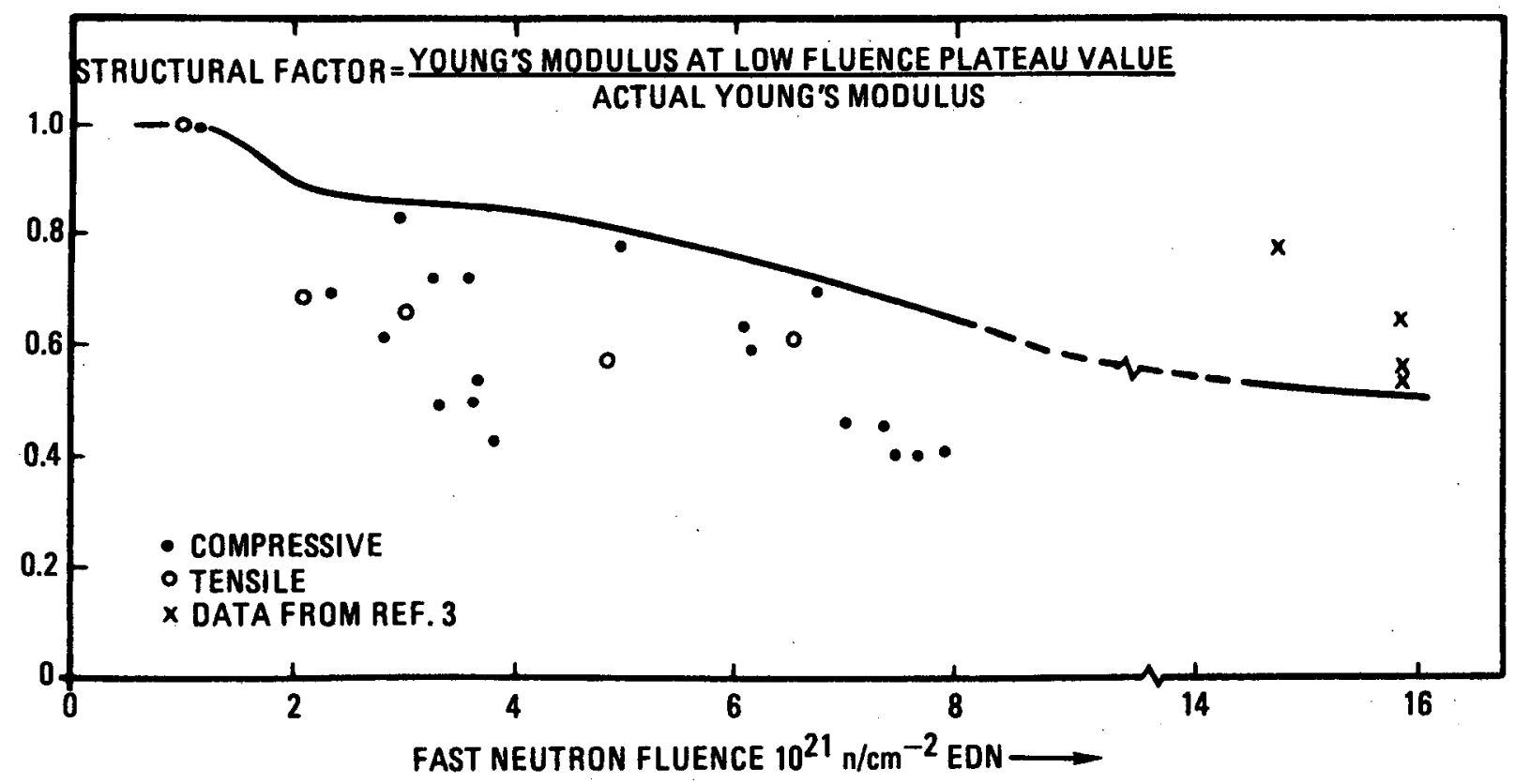

Fig. 18. Creep coefficients divided by the value at $0.8-1.4 \times 10^{21}$ $\mathrm{n} / \mathrm{cm}^{2}$, DNE, as a function of neutron fluence for ATR-ZE graphite at $500^{\circ} \mathrm{C}$, with structural factor $S$ (from Ref. 33, with added points from Ref. 3 ) 
To summarize, there appears to be a trend toward lower creep coefficients at high fluences although the data are not all consistent. There are theoretical grounds for expecting the creep coefficient to decline as Young's modulus undergoes its secondary increase, according to Eq. 7 . Two quantitative comparisons below the observed and predicted decline in the creep coefficient have been made: in one case the decline was overpredicted, and in the other case it was underpredicted. For design purposes it seems reasonable to assume that the creep coefficient decreases with neutron fluence as predicted by Eq. 7, at least until more high fluence data become available. A further reduction in creep rate is probable in compression as strains approach $2 \%$. It has not yet been determined whether the creep coefficient increases again at very high fluences where Young's modulus declines.

\subsection{TRANSVERSE STRAIN RATIO}

Kelly and Brocklehurst's analysis of irradiation creep (Ref. 3) predicts that in a uniaxially loaded specimen the ratio between the creep strain transverse to the loading axis and the creep strain parallel to the loading axis should be equal to the elastic Poisson's ratio (typically 0.1 to 0.2 ). During fully plastic creep at constant volume the ratio would be 0.5. Experimental measurements generally give a value somewhere between, with a tendency towards a higher strain ratio at high creep strain.

The mean strain ratio observed in UKAEA tests (both tension and compression) was reported to be approximately 0.3 (Ref. 5). In early stages of the Oak Ridge compressive creep tests on $\mathrm{H}-451$ graphite at $900^{\circ} \mathrm{C}$, the transverse-to-longitudinal creep strain ratio was about 0.1 to 0.2 (Ref. 25 ), but at higher strain levels the ratio increased with creep occurring at constant volume (Ref. 28); thus, the ratio between strain increments in the transverse and longitudinal directions approached 0.5. A similar ratio was reported by Gray (Ref. 38) for high-strain compressive creep in AGOT and $\mathrm{H}-337$ graphites at $550^{\circ} \mathrm{C}$. At $800^{\circ} \mathrm{C}$ the strain ratio tended to be a little lower (about 0.4). Transverse strains were also reported for the Petten 
constant load tension and compression creep tests at $500^{\circ} \mathrm{C}$ (Refs. 32 and 33). The creep strain ratio averaged $0.27 \pm 0.08$ in both tension and compression for fluences up to $5.5 \times 10^{21} \mathrm{n} / \mathrm{cm}^{2}$, DNE, and for creep strains up to about $0.6 \%$. At higher fluences the data were insuffucient to define the strain ratio.

Figure 19 shows a composite plot of transverse creep strain versus longitudinal creep strain, replotted from the references cited above. The data at low strains can be fairly well represented by a strain ratio of 0.3 ; the ratio tends to increase at higher strains. The overall relationship between the transverse creep strain, $\varepsilon_{\perp}$, and the longitudinal creep strain, $\varepsilon \mid$, can be represented by the expression

$$
\varepsilon_{\perp}=-\varepsilon \|(0.3+5 \varepsilon \|)
$$

\subsection{EFFECT OF CREEP STRAIN ON PHYSICAL PROPERTIES}

\subsubsection{Thermal Expansivity}

The thermal expansivity of isotropic graphite specimens that had undergone irradiation creep at $300^{\circ}$ to $650^{\circ} \mathrm{C}$ was measured by Brocklehurst and Brown (Ref. 36). They found that the thermal expansivity of specimens irradiated under compression increased more rapidly than that of unstressed companion specimens, while the thermal expansivity of tensile specimens increased more slowly than that of their stress-free companions. This difference in thermal expansion behavior between tensile, compressive, and

stress-free specimens could be removed by postirradiation annealing to $1400^{\circ}$ to $2000^{\circ} \mathrm{C}$. The thermal expansion of polycrystalline graphite is controlled by microcracks which absorb much of the thermal expansion of the constituent crystallites. It was suggested that the externally-applied stress modified the microcrack closure which accompanies irradiation, with compressive stresses accelerating crack closure and tensile stresses retarding crack closure. 


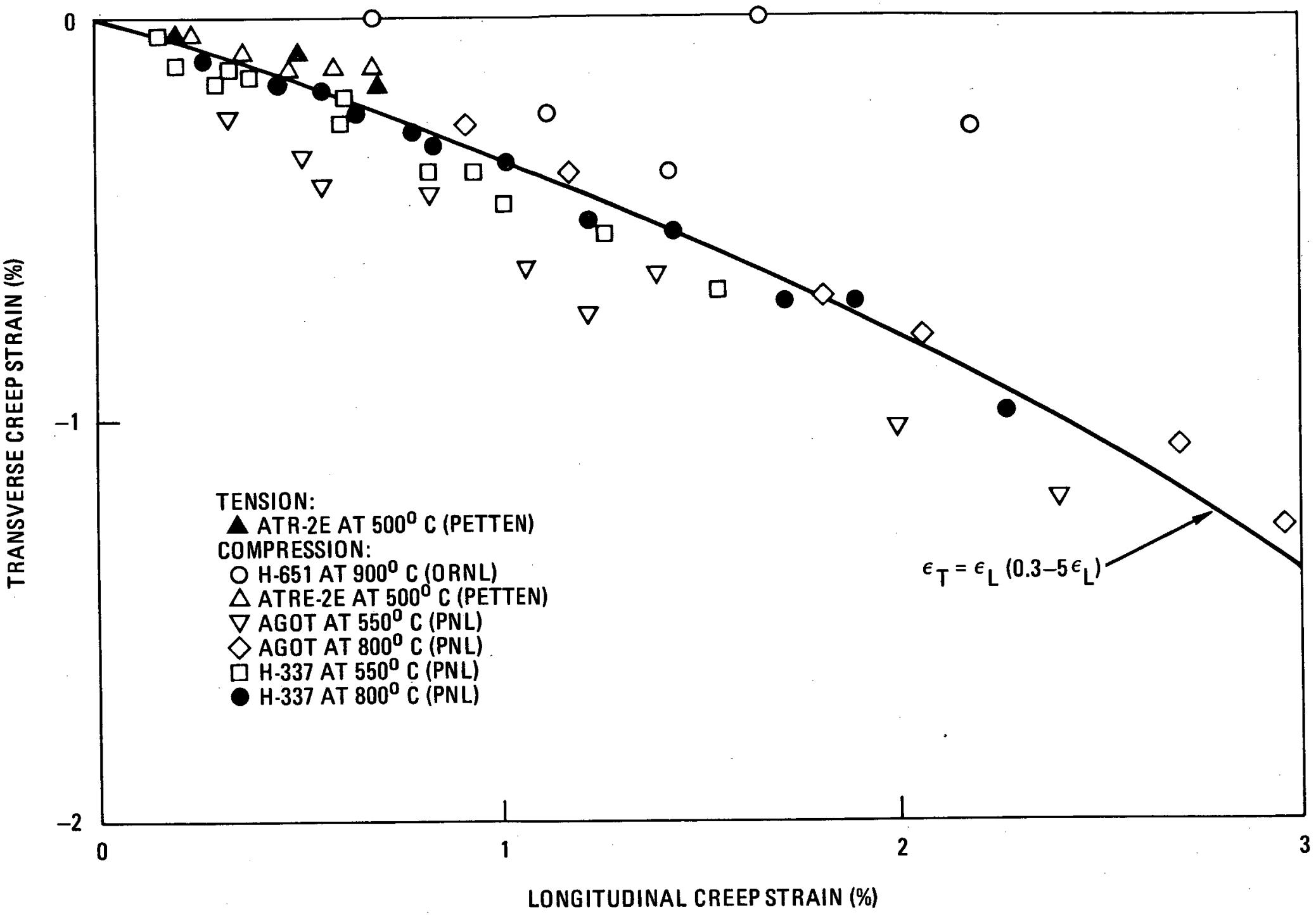

Fig. 19. Composite plot of transverse creep strain as a function of longitudinal creep strain 
This pattern of behavior has been confirmed in compressive creep specimens irradiated at Pacific Northwest Laboratories (Ref. 38) and Oak Ridge National Laboratory (Refs. 25, 27, and 28). Compressive loading increased the thermal expansivity compared with unstressed control specimens irradiated under the same conditions, with the greatest changes occurring at high creep strains. Greater fractional increases in thermal expansivity were seen in the needle coke graphite grades AGOT and $\mathrm{H}-327$ (which have low initial expansivity) than in the near-isotropic grades $\mathrm{H}-337$ and $\mathrm{H}-451$. It was also noted (Refs. 25 and 27) that creep increased both the temperaturedependent and the temperature-independent components of thermal expansivity.

The continuously monitored tensile creep tests at Grenoble and Petten (Refs. 19 and 22) confirmed the UKAEA observation of lower thermal expansivity in tensile creep specimens than in unstressed companions. The magnitude of the effect was similar to the earlier UKAEA work.

The data from the references cited above are replotted in Figs. 20 and 21 . Figure 20 shows the thermal expansivity of a creep specimen, $\alpha_{c}$, divided by the thermal expansivity of an unstressed companion irradiated under the same conditions, $\alpha_{0}$, plotted against the creep strain, for nearisotropic graphite grades. Figure 21 is a similar plot for needle coke graphites. For near-isotropic graphites the thermal expansivity change, $\alpha_{c} / \alpha_{0}$, may be related to the creep strain, $\varepsilon_{c}$ (considering compressive strain to be negative and tensile strain positive), by the expression

$$
\frac{\alpha_{c}}{\alpha_{0}}=\left(1-18 \varepsilon_{c}\right)
$$

For needle coke graphites the dependence on creep strain is greater and may be represented by

$$
\frac{\alpha_{c}}{\alpha_{0}}=\left(1-30 \varepsilon_{c}\right) \text {. }
$$




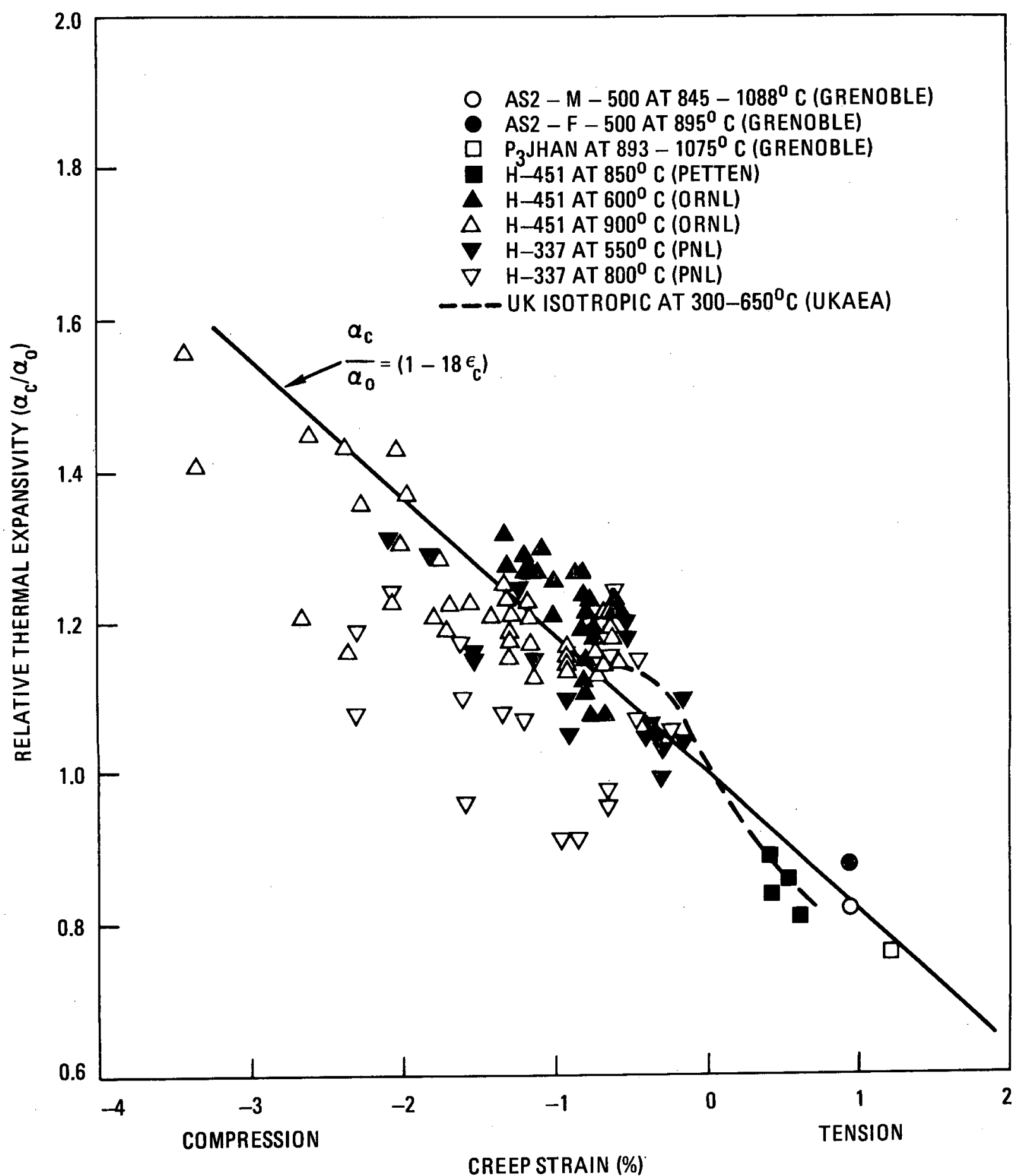

Fig. 20. Composite plot of thermal expansivity of creep specimens divided by the thermal expansivity of irradiated unstressed companion specimens, as a function of creep strain (nearisotropic graphites) 


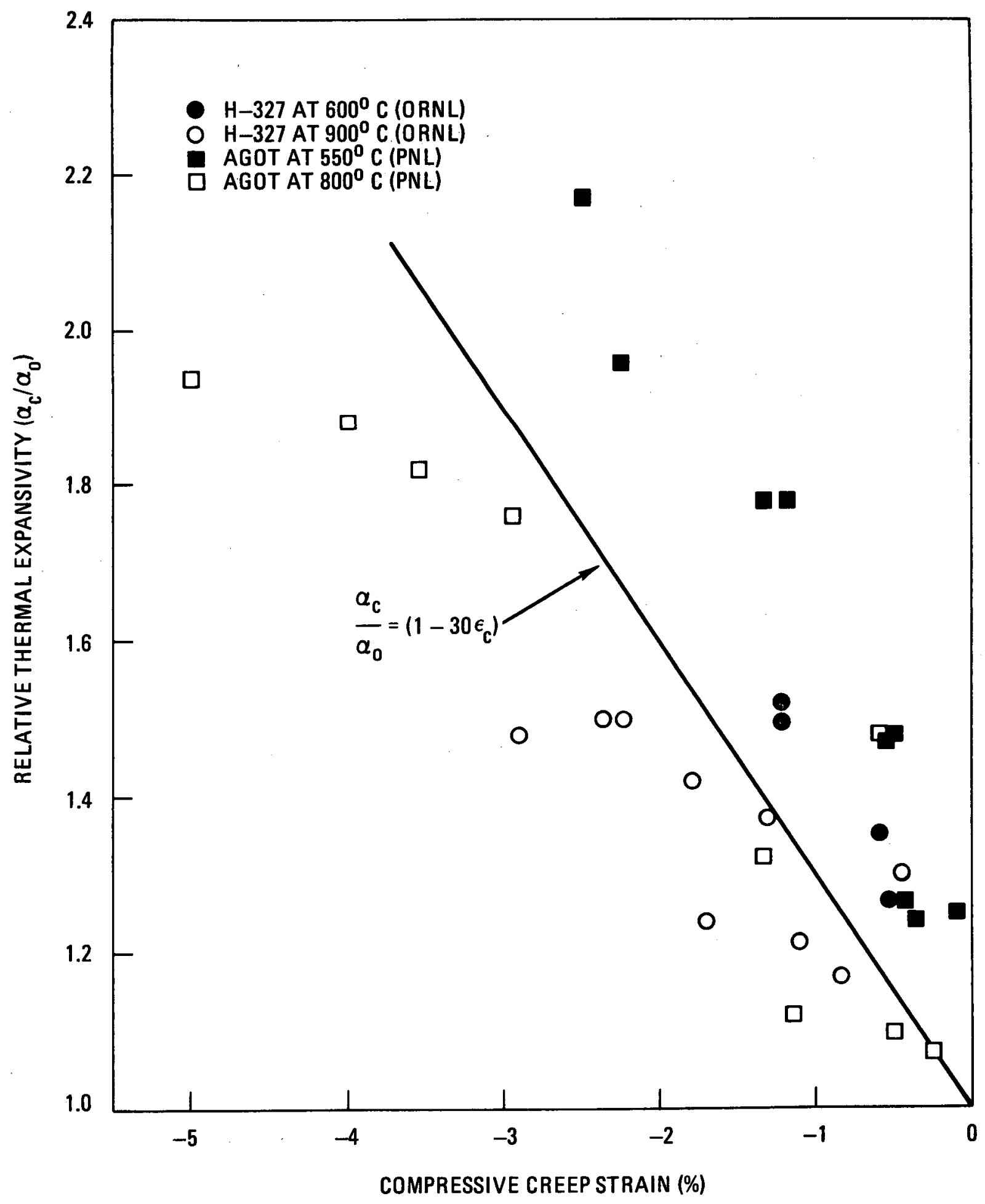

Fig. 21. Composite plot of thermal expansivity of creep specimens divided by the thermal expansivity of irradiated unstressed companion specimens, as a function of creep strain (needle coke graphites) 
Figure 21 also appears to show that the fractional changes tend to be higher at $550^{\circ}$ to $600^{\circ} \mathrm{C}$ than at $800^{\circ}$ to $900^{\circ} \mathrm{C}$. However, the comparison is not straightforward because the thermal expansion tests were made over different temperature ranges and the temperature dependence of the expansion coefficient may be altered by the creep strain, as noted above.

\subsubsection{Young's Modulus}

The early UKAEA work by Brocklehurst and Brown (Ref. 36) included measurements of Young's modulus on tensile and compressive creep specimens. Within the scatter of the data, no difference could be seen between Young's modulus changes in tensile, compressive, and unstressed specimens. The tensile creep specimens from the Grenoble and Petten experiments (Refs. 19 and 22) also showed very little difference in Young's modulus between stressed and unstressed specimens, although the Petten tests on $\mathrm{H}-45 \mathrm{l}$ graphite showed a tendency toward a higher Young's modulus in the tensile specimens. The first set of Oak Ridge compressive creep tests at $900^{\circ} \mathrm{C}$ (Ref. 25) appeared to indicate a marked tendency toward a lower Young's modulus in the stressed specimens than in their unstressed companions. However, this trend was largely due to the behavior of "overstressed" specimens in a column which experienced high but unknown stresses due to a jammed load system (Ref. 28). Later tests at $900^{\circ}$ and $600^{\circ} \mathrm{C}$ (Refs. 27 and 28) showed a smaller difference in Young's modulus between stressed and unstressed specimens, although there was still a tendency toward lower values at high creep strains.

The data from all these tests are replotted in Fig. 22, where the ratio between Young's modulus of a creep specimen $\left(E_{C}\right)$ and Young's modulus of an unstressed companion $\left(E_{O}\right)$ is plotted against the creep strain $\left(\varepsilon_{c}\right)$. If the overstressed points are excluded, the data can be represented by the relation

$$
\frac{E_{c}}{E_{o}}=\left(1+3 \varepsilon_{c}\right) \text {. }
$$




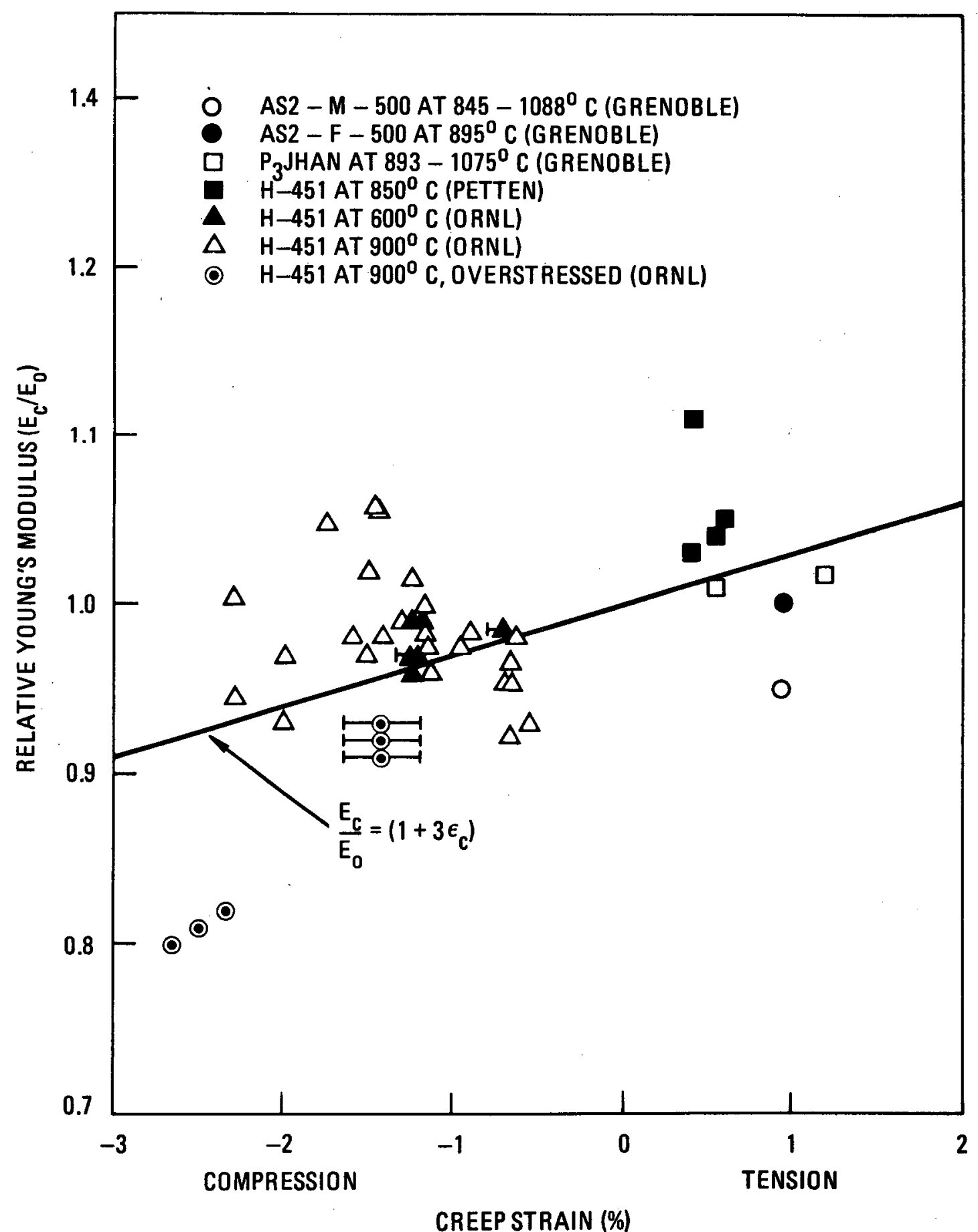

Fig. 22. Composite plot of Young's modulus of creep specimens divided by Young's modulus of Irradiated unstressed companion specimens, as a function of creep strain (near-isotopic graphites) 


\subsubsection{Poisson's Ratio}

Following the Oak Ridge compressive creep tests, Poisson's ratio of the specimens was derived from sonic measurements of Young's modulus and the shear modulus (Refs. 25 and 27). While Poisson's ratio of unstressed specimens was unaffected by irradiation, the creep specimens underwent a progressive decrease in Poisson's ratio. The results are shown in Fig. 23 (data from Refs. 25 and 27), plotted as a function of compressive creep strain. The three near-zero Poisson's ratio points at about $2.5 \%$ strain are from the overstressed specimens. Neglecting these three points, the data can be represented by

$$
\frac{\nu_{c}}{\nu_{o}}=\left(1+30 \varepsilon_{c}\right) \text {, }
$$

where $\nu_{c}$ and $\nu_{0}$ are Poisson's ratios of a creep specimen and a control specimen, respectively, and $\varepsilon_{c}$ is the creep strain (negative value for compressive strain).

\subsubsection{Strength and Failure Strain}

The strain-to-failure of a tensile specimen of typical nuclear graphite, tested in the laboratory, is typically $0.1 \%$ to $0.2 \%$. Under irradiation creep, tensile strains up to $1.8 \%$ without fracture have been reported (Ref. 12). Oxidized specimens can withstand even greater creep strains; a creep strain exceeding $7.5 \%$ under an applied stress of $6 \mathrm{MPa}$ has been reported in one case. The specimen remained intact, although visibly deteriorated (Ref. 39). A few tensile creep specimens have fractured in the reactor during restrained shrinkage or controlled load tests, but such fractures have always been attributable to inadvertent stressing beyond the tensile strength. There was no evidence that any specimen had reached a tensile strain limit. 


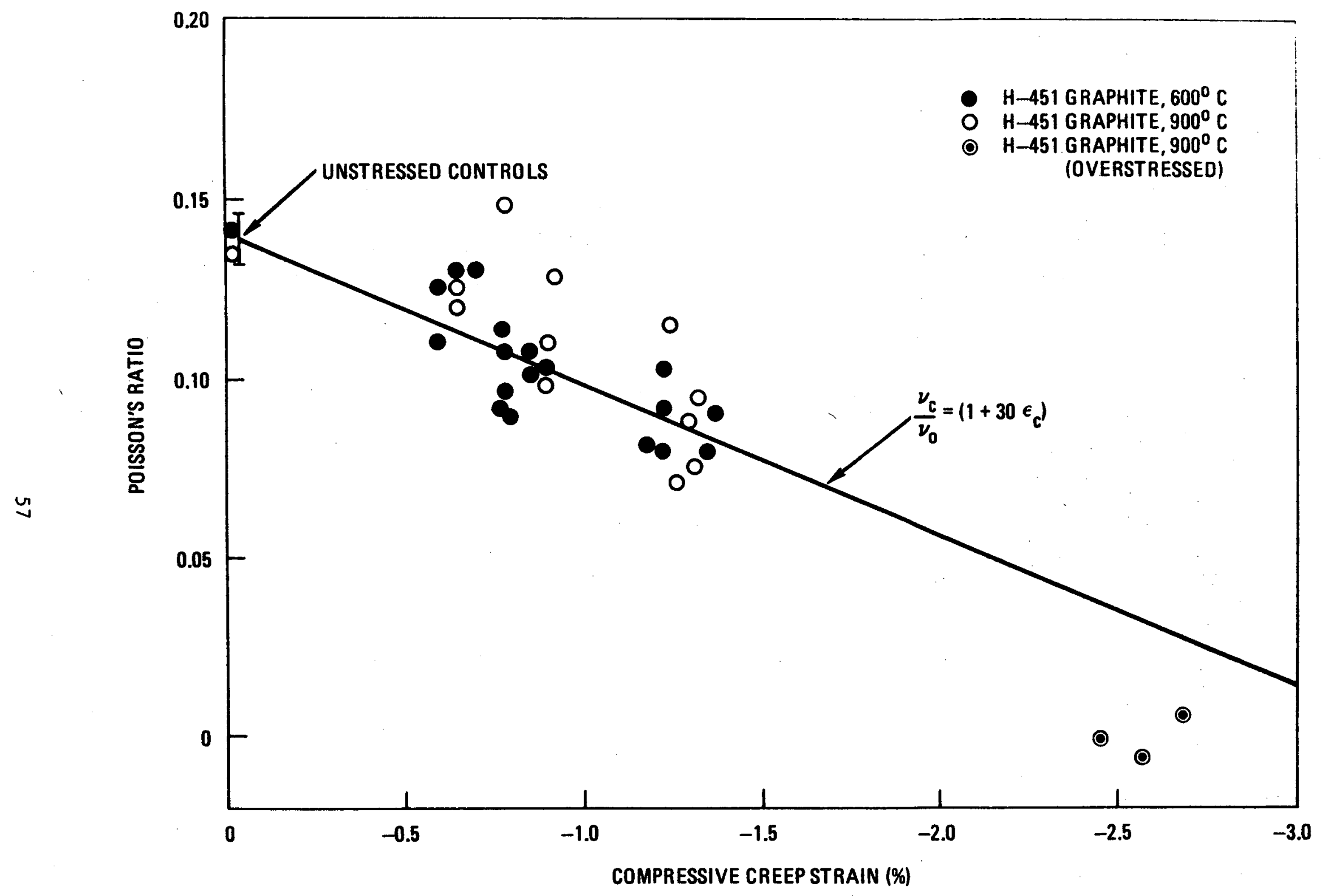

F1g. 23. Polsson's ratio of creep specimens divided by Poisson's ratio of irradiated unstressed companion specimens, as a function of creep strain (H-451 graphite; data from Ref. 25 and 27) 
Very little data are available on the effect of creep strain on the tensile strength. Manzel et a1. (Ref. 35) reported the strength of six specimens of a pressed gilsocarbon graphite creep-tested in the Dragon reactor, together with two unstressed companions irradiated under the same conditions. The irradiation temperature was $850^{\circ} \mathrm{C}$ for four specimens and $1240^{\circ} \mathrm{C}$ for the remaining four. The measured strengths are plotted against creep strain in Fig. 24. The tensile strength appears to be unaffected by creep strain. Additional indirect evidence that this is the case comes from measurements of the sonic attenuation on compressive creep specimens at Oak Ridge National Laboratory (Ref. 28). The sonic attenuation is related to the size of defects in the material, and correlates well with the tensile strength of many graphites. The sonic attenuation was the same in the creep specimens as in their unstressed companions, indicating that the tensile strength is probably unaffected by compressive creep strain.

\subsubsection{Irradiation-Induced Dimensional Change Rates}

Figure 25 shows the dimensional changes in specimens of UK isotropic graphite as a function of fluence, taken from Ref. 5. One specimen was irradiated under a tensile load for the first part of the test period, one was irradiated for a time under a compressive load, and two were unstressed companions. After removal of the load, a portion of the creep strain was recovered and the dimensional change curves for the formerly stressed specimens approached those of the unstressed specimens (see Subsection 5.1). The major part of the creep strain remained in the specimens after recovery had saturated, but the dimensional change rates appear to have been the same as those of the unstressed companions at the same total neutron fluence. Thus, unrecovered creep strain appears to have no effect on the rate of radiation damage accumulation in a subsequent stress-free irradiation. 

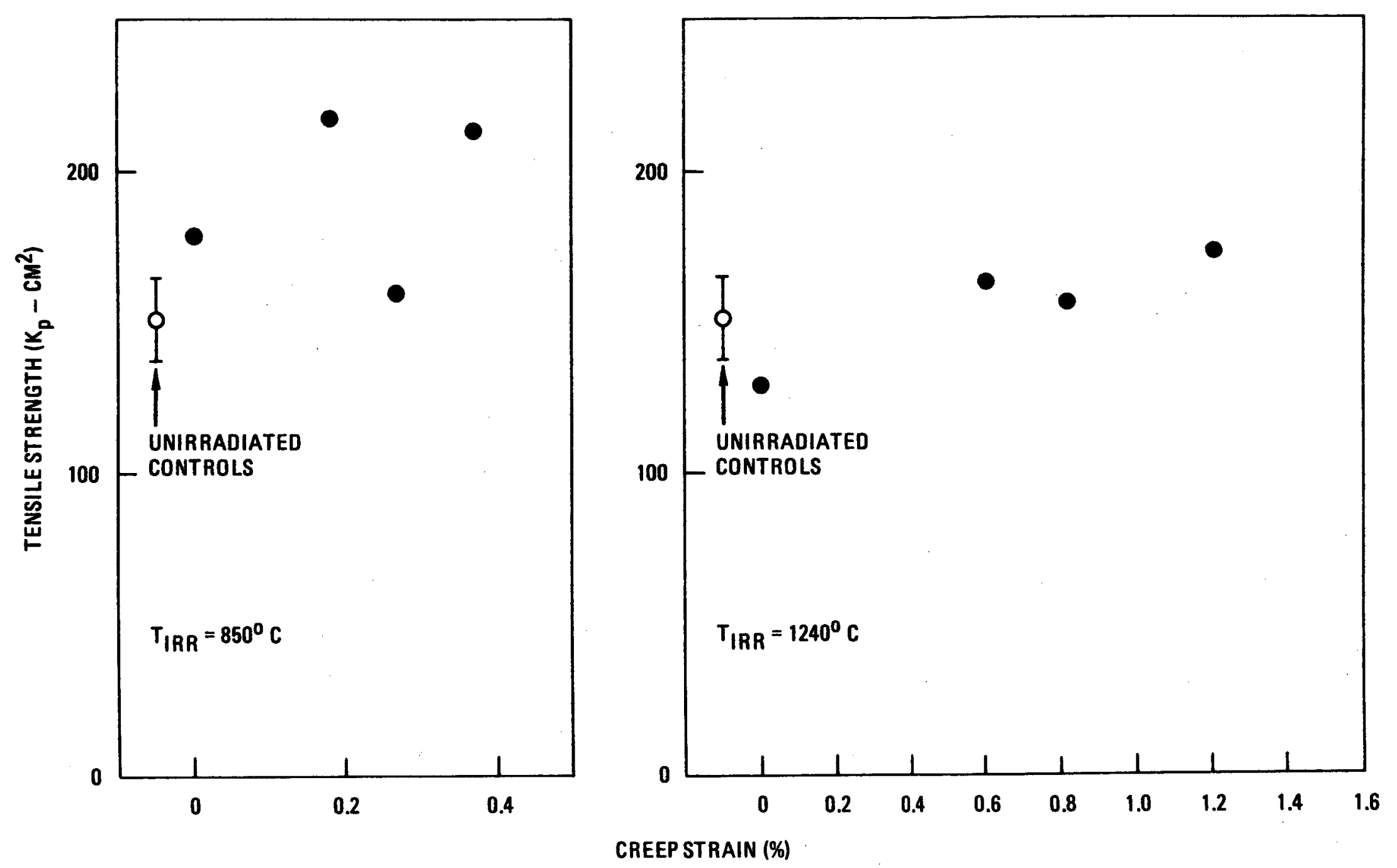

Fig. 24. Tensile strength of creep specimens of pressed gilsocarbon graphite Irradiated in the Dragon reactor, as a function of tensile creep strain (data from Ref. 35). 


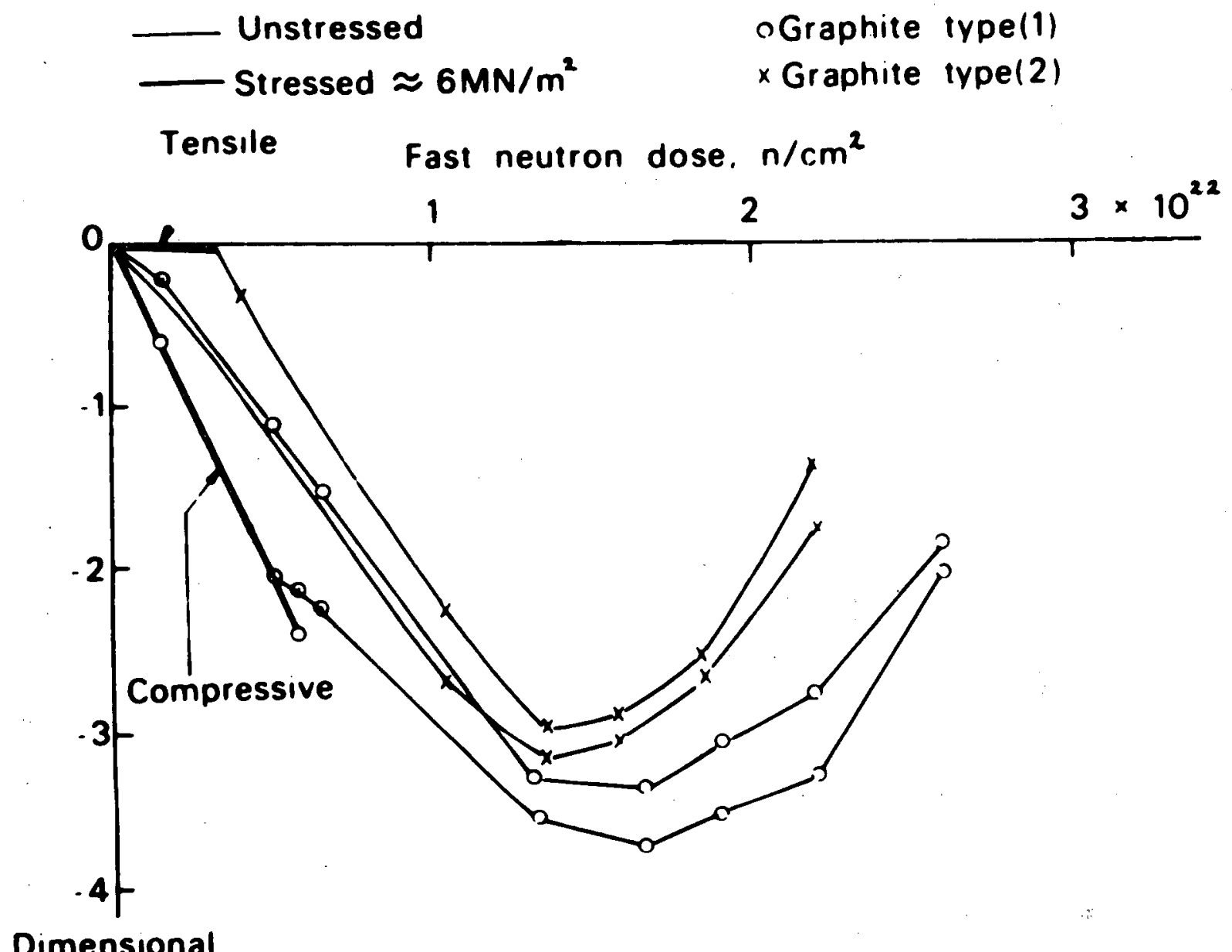

change. \%

Fig. 25. Dimensional changes as a function of neutron fluence of UK isotropic graphite specimens subjected to a tensile or compressive load for the first part of the irradiation, with unstressed controls (from Ref. 5) 


\section{RECOMMENDED DESIGN EQUATIONS}

\subsection{CREEP MODEL}

The basic elements of the linear viscoelastic creep model represented by Fig. 1 and Eq. 1 should be retained, except that the steady-state creep coefficient, $k$, should be treated as different for tensile and compressive loading and as a function of fluence. Most of the other basic features of the model have been verified reasonably well by experiments. These features include a transient creep stage followed by a steady-state creep stage, slow recovery of the transient creep strain when the load is removed during irradiation, and linear dependence of both transient and steady-state creep strain on the applied stress. A portion of the steady-state creep strain, in addition to the transient creep strain, may be recoverable, but it is not possible at present to say how much.

\subsection{TRANSIENT CREEP}

The total transient creep strain is approximately equal to the elastic strain, independent of irradiation temperature. The transient creep strain, $\varepsilon_{\mathrm{T}}$, may be represented by

$$
\varepsilon_{T}=\frac{\sigma}{E}[1-\exp (-b \gamma)],
$$

where $\sigma$ is the applied stress and $E$ is Young's modulus when the load is applied or changed. For virgin material, $E$ is the value for unirradiated graphite, but for irradiated material $E$ is the value for the appropriate 
fluence and irradiation temperature. The value for $b$, in the various fluence units currently being used, is

$$
\begin{aligned}
& \mathrm{b}=0.35 \times 10^{-19}\left(\mathrm{n} / \mathrm{cm}^{2}, \mathrm{DNE}\right)^{-1} \\
& =0.20 \times 10^{-19}\left(\mathrm{n} / \mathrm{cm}^{2}\right. \text {, equivalent fission fluence for damage in } \\
& \text { graphite })^{-1} \\
& =0.25 \times 10^{-19}\left(\mathrm{n} / \mathrm{cm}^{2}, \mathrm{E}>0.18 \mathrm{Mev}, \mathrm{HTGR}\right)^{-1} \text {. }
\end{aligned}
$$

\subsection{STEADY STATE CREEP}

The experimental data reviewed in Subsection 5.2 lead to the following conclusions about steady-state creep:

1. Creep rates in tension are about $25 \%$ higher than creep rates in compression.

2. At low fluences the creep rate is inversely proportional to the unirradiated Young's modulus.

3. There is no conclusive evidence for a flux-dependent creep coefficient.

4. The best representation of the temperature dependence of the creep coefficient in near-isotropic graphites such as H-451 is the UKAEA line given by Eq. 5 .

5. The change in creep coefficient with neutron fluence correlates with the change in Young's modulus according to Eq. 7 . 
Based on these conclusions, the following expression for the steady-state creep strain, $\varepsilon_{S}$, is recommended:

$$
\begin{aligned}
& T<650^{\circ} \mathrm{C}: \frac{d \varepsilon_{S}}{d \gamma}=\frac{\sigma E^{*} c}{E_{o} E(\gamma, T)}, \\
& T>650^{\circ} \mathrm{C}: \frac{d \varepsilon_{S}}{d \gamma}=\frac{\sigma E^{*}\left[c+d(T-650)^{2.6}\right]}{E_{o} E(\gamma, T)},
\end{aligned}
$$

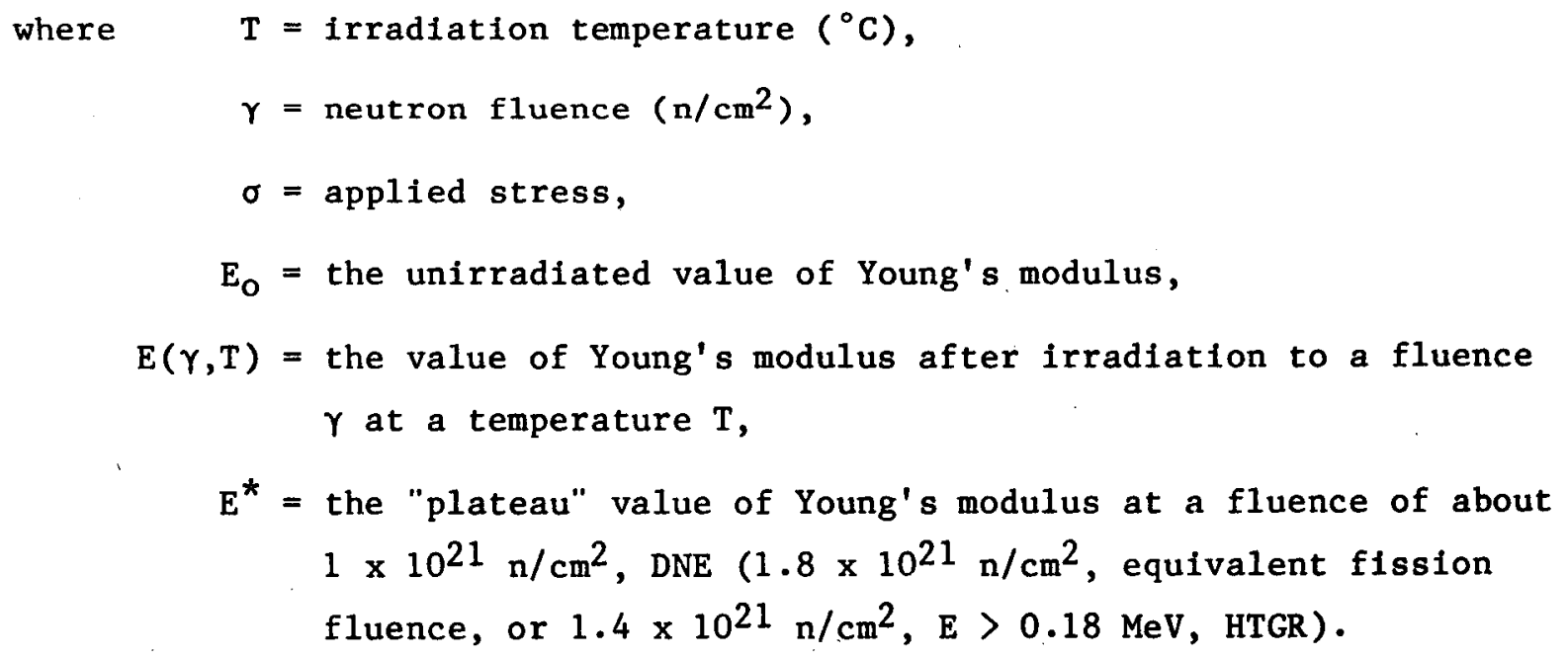

Stress and Young's modulus must be expressed in the same units. Values for $c$ and $d$ are listed in Table 3 for tension and compression, and for various fluence units. Equation 14 can be assumed valid at temperatures between $300^{\circ}$ and $1100^{\circ} \mathrm{C}$, and for total creep strains up to $2 \%$.

\subsection{TRANSVERSE STRAIN RATIO}

The recommended value for the transverse creep strain, $\varepsilon_{\perp}$, can be calculated from Eq. 8:

$$
\varepsilon_{\perp}=-\varepsilon_{\|}\left(0.3+5 \varepsilon_{\|}\right),
$$

where $\varepsilon_{\|} \mid$is the longitudinal creep strain. 
TABLE 3

VALUES FOR STEADY-STATE CREEP PARAMETERS

(in Eq. 14)

\begin{tabular}{|c|c|c|c|}
\hline $\begin{array}{l}\text { Stress } \\
\text { Direction }\end{array}$ & Parameter & F1uence Units & $\begin{array}{l}\text { Parameter Value } \\
\qquad\left(\mathrm{n} / \mathrm{cm}^{2}\right)^{-1}\end{array}$ \\
\hline \multirow[t]{6}{*}{ Tension } & c & Dido Nickel Equivalent (DNE) & $2.6 \times 10^{-21}$ \\
\hline & & $\begin{array}{l}\text { Equivalent Fission Fluence } \\
\text { for Damage in Graphite (EFFDG) }\end{array}$ & $1.5 \times 10^{-21}$ \\
\hline & & E $>0.18 \mathrm{MeV}$, HTGR spectrum & $1.8 \times 10^{-21}$ \\
\hline & d & DNE & $7.8 \times 10^{-28}$ \\
\hline & & EFFDG & $4.4 \times 10^{-28}$ \\
\hline & & $\mathrm{E}>0.18 \mathrm{MeV}$, HTGR & $5.5 \times 10^{-28}$ \\
\hline \multirow[t]{6}{*}{ Compression } & c & & $2.0 \times 10^{-21}$ \\
\hline & & EFFGD & $1.2 \times 10^{-21}$ \\
\hline & & $E>0.18 \mathrm{MeV}$, HTGR & $1.4 \times 10^{-21}$ \\
\hline & d & DNE & $6.2 \times 10^{-28}$ \\
\hline & & EFFGD & $3.5 \times 10^{-28}$ \\
\hline & & $\mathrm{E}>0.18 \mathrm{MeV}, \mathrm{HTGR}$ & $4.4 \times 10^{-28}$ \\
\hline
\end{tabular}




\subsection{EFFECT OF CREEP STRAIN ON PHYSICAL PROPERTIES}

The thermal expansivity $(\alpha)$, Young's modulus (E), and Poisson's ratio $(\nu)$ of graphite subjected to a creep strain will differ slightly from those of an unstressed companion at the same irradiation conditions. The relative difference in property can be estimated from Eqs. 9 through 12. For nearisotropic graphites (including grade H-451) the following expressions apply:

$$
\begin{aligned}
& \frac{\alpha_{c}}{\alpha_{0}}=\left(1-18 \varepsilon_{0}\right), \\
& \frac{E_{0}}{E_{0}}=\left(1+3 \varepsilon_{c}\right), \\
& \frac{\nu_{c}}{\nu_{0}}=\left(1+30 \varepsilon_{c}\right),
\end{aligned}
$$

where $\varepsilon_{c}$ is the creep strain (positive for tensile, negative for compressive). The subscripts $c$ and o respectively indicate a creep specimen and an unstressed specimen irradiated under the same conditions. For needle coke graphites (such as grade $\mathrm{H}-327$ ) the expression for thermal expansivity is different:

$$
\frac{\alpha_{c}}{\alpha_{0}}=\left(1-30 \varepsilon_{c}\right)
$$

The tensile strength and rate of irradiation-induced dimensional change can be assumed to be unaffected by creep strain. 


\section{REFERENCES}

1. Price, R. J., "Review of Irradiation-Induced Creep in Graphite under HTGR Conditions," General Atomic Report GA-A12332, November 1; 1972 .

2. Measurement of Irradiation-Enhanced Creep in Nuclear Materials, (Proc. International Conference, Petten, The Netherlands, May 5-6, 1976) (ed. M. R. Cundy, P. Von der Hardt, and R. H. Loelgen), North Holland Publishing Company, Amsterdam, 1977. (Also published in J. Nucl. Mater., 65, 1977.)

3. Kelly, B. T., and J. E. Brocklehurst, "Analysis of Irradiation Creep in Reactor Graphite," Proc. Third Conference on Industrial Carbons and Graphite, Soclety of Chemical Industry, London, 1971, p. 363.

4. Kelly, B. T., and A. J. E. Foreman, "The Theory of Irradiation Creep in Reactor Graphite - The Dislocation Pinning-Unpinning Mode1," Carbon, 12,151 (1974).

5. Kelly, B. T., and J. E. Brocklehurst, "UKAEA Reactor Group Studies of Irradiation-Induced Creep in Graphite," J. Nuc1. Mater., 65, 79 (1977).

6. Morgan, W. C., "Neutron Fluence and Atomic Displacement Rates for Graphite Irradiations," Nuc1. Techno1., 21, 50 (1974).

7. Roberts, A. C., and A. H. Cottre11, "Creep of Alpha Uranium during Irradiation with Neutrons," Phil. Mag., 1, 711 (1956).

8. Brocklehurst, J. E., "The Irradiation Induced Creep of Graphite under Accelerated Damage Produced by Boron Doping," Carbon, 13, 421 (1975).

9. Cords, H., R. Zimmermann, and G. Kleist, "Model Analysis of Irradiation-Induced Creep Experiments," Extended Abstracts of the 14th Biennial Conference on Carbon, p. 455 (American Carbon Society, 1979).

10. Cords, H., and R. Zimmermann, "A Model for Irradiation Induced Changes in Graphite Material Properties," Proc. 5th London International Carbon and Graphite Conference, v. II, Society of Chemical Industry, London, 1978 , p. 918. 
11. Veringa, H. J., and R. Blackstone, "High Temperature IrradiationEnhanced Creep in Graphites for HTR Applications," Extended Abstracts of the 12th Biennial Conference on Carbon, p. 143 (American Carbon Society, 1975).

12. Veringa, H. J., and R. Blackstone, "The Irradiation Creep in Reactor Graphites for HTR Applications," Carbon, 14, 279 (1976).

13. Veringa, H. J., "The Irradiation-Induced Creep in Graphites for HTR Applications," Carbon, 76, p. 322 (Deutsche Keramische Gesellschaft, 1976).

14. Blackstone, R., "Radiation Creep in Graphite: An Introduction," J. Nuc1. Mater., 65, 72 (1977).

15. Blackstone, R., L. W. Graham, and M. R. Everett, "High Temperature Radiation Induced Creep in Graphite," Dragon Project Report D.P. 665, 1969.

16. Kleist, G., et a1., "Continuously Measured Irradiation Creep Strain of Two Reactor Grade Graphites," Carbon, 76, p. 345 (Deutsche Keramische Gesellschaft, 1976).

17. Masson, M., "Graphite High Temperature Creep Rigs," J. Nuc1. Mater., 65,142 (1977).

18. Jouquet, G., G. Kleist, and H. Veringa, "Review of a Test Program on Irradiation Creep of Graphites and Systemization of Results," J. Nucl. Mater., 65, 86 (1977).

19. Jouquet, $\bar{G}_{\text {. }}$, et a1., "Continuously Measured Irradiation Creep Strain of Two Reactor Graphites," High Temperatures-High Pressures, 9, 151 (1977).

20. Hansen, H., R. Lolgen and M. Cundy, "Uniaxial Tensile Graphite Creep Capsules with Continuous Strain Registration," J. Nucl. Mater., 65, 148 (1977).

21. Veringa, H., and M. R. Cundy, "Irradiation Creep and Its Flux Dependence on Near Isotropic Graphite at $850^{\circ} \mathrm{C}, "$ Extended Abstracts of the 13th Biennial Conference on Carbon, p. 344 (American Carbon Society, 1977). 
22. O'Connor, M. F., et al., "FRG/US Cooperation on the Characterization of Reactor Graphites," Carbon, 80, p. 586 (Deutsche Keramische Gesellschaft, 1980).

23. Senn, R. L., et al., "Design, Operation, and Initial Results from a Series of Graphite Creep Irradiation Experiments," J. Nucl. Mater., 65, 96 (1977).

24. Senn, R. L., et al., "Design and Operation of a Graphite Creep Irradiation Experiment," Extended Abstracts of the 13th Biennial Conference on Carbon, p. 340 (American Carbon Society, 1977).

25. Kennedy, C. R., W. H. Cook, and W. P. Eatherly, "Results of Irradiation Creep Testing Graphite at $900^{\circ} \mathrm{C}, "$ ibid., p. 342 .

26. Senn, R. L., and J. A. Conlin, "Operation and Control of the Second of a Series of Graphite Creep Irradiation Experiments," Extended Abstracts of the 14th Biennial Conference on Carbon, p. 451 (American Carbon Society, 1979).

27. Kennedy, C. R., and W. P. Eatherly, "Results of the $600^{\circ} \mathrm{C}$ Compressive Creep Irradiation Experiment," ibid., p. 453.

28. Kennedy, C. R., W. P. Eatherly, and R. L. Senn, "Compressive Creep Characteristics of Graphite under Irradiation," presented at the 33rd Pacific Coast Regional Meeting of the American Ceramic Society, San Francisco, Oct. 26-29, 1980.

29. Lölgen, R., and F. Mason, "Reloadable Graphite Creep Fac1lity for Tensile or Compressive Experiments," J. Nucl. Mater., 65, 131 (1977).

30. Cundy, M. R., et al., "Irradiation Creep in Graphite at $500^{\circ} \mathrm{C}, "$ Proc. 5 th London International Carbon and Graphite Conference, II, Society of Chemical Industry, 1978, p. 959.

31. Kleist, G., M. F. O'Connor, and M. R. Cundy, "High Fluence Graphite Creep Experiments Relevant for the Pebble Bed HTR," Extended Abstracts of the 14th Biennial Conference on Carbon, p. 457 (American Carbon Society, 1979).

32. Klelst, G., and M. F. O'Connor, "Irradiation Creep Performance of Graphite Relevant for Pebble Bed HTRs," Proc. Specialists Meeting on Mechanical Behavior of Graphite for HTRs, Gif-sur-Yvette, France, June 11-13, 1979, p. 103 (IAEA Report IWGHTR/3, 1980). 
33. Cundy, M. R., M. F. O'Connor, and G. Kleist, "High Fluence Creep Behavior of Near Isotropic Pitch Coke Graphite," Carbon, 80, p. 569 (Deutsche Keramische Gesellschaft, 1980).

34. Manzel, R., M. R. Everett, and L. W. Graham, "A High Temperature Graphite Irradiation Creep Experiment in the Dragon Reactor," Extended Abstracts of the 10th Biennial Conference on Carbon, p. 178 (American Carbon Committee, 1971).

35. Manze1, R., M. R. Everett, and L. W. Graham, "A High Temperature Graphite Irradiation Creep Experiment in the Dragon Reactor," Dragon Project Report DP-752, 1971.

36. Brocklehurst, J. E., and R. G. Brown, "Constant Stress Irradiation Creep Experiments on Graphite in BR-2," Carbon, 7, 487 (1969).

37. Perks, A. J., and J. H. W. Simmons, "Dimensional Changes and Radiation Creep of Graphite at Very High Doses," Carbon, 4, 85 (1966).

38. Gray, W. J., "Constant Stress Irradiation-Induced Compressive Creep of Graphite at High Fluences," Carbon, 11, 383 (1973).

39. Gray, B. S., et a1., "The Irradiation-Induced Plasticity of Graphite under Constant Stress," Carbon, 5, 173 (1967). 
